\title{
Glycodendrimers as chondroitin sulfate mimetics: synthesis and binding to growth factor midkine
}

\author{
Pedro Domínguez-Rodríguez, ${ }^{[a]}$ José J. Reina, ${ }^{[a, b]}$ Sergio Gil-Caballero, ${ }^{[a]}$ Pedro M. Nieto, ${ }^{*[a]}$ José L. de \\ Paz, ${ }^{*[a]}$ and Javier Rojo*[a]
}

\begin{abstract}
Chondroitin sulfate (CS) is a member of the glycosaminoglycan (GAG) family, a class of polysaccharides implicated in relevant biological functions. The structural complexity of these carbohydrates demands the development of simple glycomimetics as useful tools to study the biological processes where GAGs are involved. In this work we described the synthesis of the disaccharide unit of the CS-E (GlcA-GalNAc(4,6-di-OSO 3 )), in a multivalent presentation. Using a fluorescence polarization competition assay we have demonstrated that a hexavalent dendrimer of this disaccharide interact with midkine, in the low micromolar range. This result highlights the potency of these disaccharide-displaying multivalent systems as interesting mimetics of longer and synthetically more complex GAG oligosaccharides.
\end{abstract}

\section{Introduction}

Chondroitin sulfate (CS) is a sulfated and very heterogeneous polysaccharide that belongs to the glycosaminoglycan (GAG) family. ${ }^{[1]} \mathrm{CS}$ is involved in numerous biological processes, such as cancer, neuroregeneration and inflammation. The biological functions of this biopolymer are due to the interactions between CS oligosaccharide sequences, with a particular chemical structure, mainly in terms of sulfation pattern, and a wide range of proteins. ${ }^{[2]}{ }^{[3]}$ For example, it is well known that natural CS chains enriched in the $E$ sulfate group distribution, characterized by the disaccharide GlcA-GalNAc(4,6-di-OSO $)$, strongly interact with several heparin-binding growth factors. ${ }^{[4]}$

For this reason, there is a great demand for the synthesis of homogeneous CS oligosaccharides and analogs, containing well-defined structures that potentially enhance protein binding and activity. ${ }^{[5]}$ However, the synthesis of large CS oligomers is a challenging and complex process. Therefore, the development of novel glycomimetics that retain, or even increase, the biological activity of natural sequences and, at the same time,

[a] P. Domínguez-Rodríguez, Dr. J.J. Reina, Dr. S. Gil-Caballero, Dr. P. M. Nieto, Dr. J.L. de Paz and Dr. J. Rojo Instituto de Investigaciones Químicas (IIQ) CSIC - Universidad de Sevilla

Américo Vespucio 49, 41092 Seville, Spain

E-mail:pedro.nieto@iiq.csic.es; ilpaz@iiq.csic.es: javier.rojo@iiq.csic.es

[b] Current address: Singular Research Centre in Chemical Biology and Molecular Materials (CIQUS)

Organic Chemistry Department, University of Santiago de

Compostela (USC), Santiago de Compostela, Spain

Supporting information for this article is given via a link at the end of the document. can be easily prepared in comparison with the natural oligosaccharides is highly desirable. These strategies greatly facilitate the access to compounds for testing and modulating CS functions. Inspired by nature, multivalency is an efficient strategy to create new glycoconjugates with the aim to increase in an easy way the low affinities that monovalent carbohydrate ligands present. ${ }^{[6]}$ Although there are many examples concerning the preparation and use of these carbohydrate multivalent systems, ${ }^{[6 c, 7]}$ actually, only a few studies on the preparation of GAG/CS mimetics by incorporation of synthetic sugars to multivalent scaffolds have been reported. ${ }^{\left[{ }^{[8]}\right.}$ For example, Hsieh-Wilson and coworkers described the generation of polymers functionalized with CS di- and tetrasaccharides that inhibited the outgrowth of neurons and strongly bound to several growth factors, mimicking the activity of the natural polysaccharide. ${ }^{[9]}$ Recently, Lee and coworkers have shown the preparation of a series of glycopeptides that display CS disaccharide motifs, studying their specific interaction with nerve growth factor (NGF) and demonstrating the ability of some of these structures to stimulate neurite growth. ${ }^{[10]}$

Here, we report the preparation of novel dendrimers bearing CS E disaccharide units. These multivalent monodisperse systems were efficiently synthesized by taking advantage of $\mathrm{Cu}$ (I) catalyzed cycloaddition reaction between azide-functionalized sugars and a set of alkyne-terminated dendrimer cores. Additionally, we have evaluated the protein binding affinities of these compounds, demonstrating that the multivalent presentation of the sugar epitopes on the dendritic scaffold strongly enhanced their recognition by the growth factor midkine.

\section{Results and Discussion}

First, we accomplished the synthesis of disaccharides 12 and 4 (Scheme 1), the conveniently functionalized sulfated carbohydrate ligands selected for the assembly of the corresponding glycodendrimers. For this aim, trichloroacetimidate $\mathbf{5}^{[11]}$ was efficiently glycosylated with 3azidopropanol to afford monosaccharide $\mathbf{6}$ that displayed a suitable linker for further conjugation with alkyne-terminated dendritic cores. 


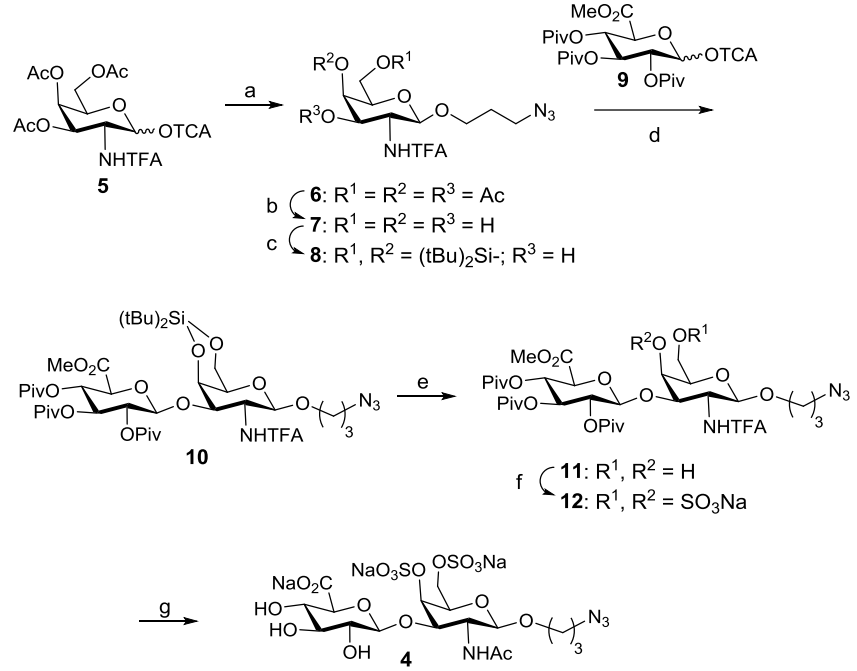

Scheme 1. Reagents and conditions: a) 3-azidopropanol, TMSOTf, $\mathrm{CH}_{2} \mathrm{Cl}_{2}$, $0^{\circ} \mathrm{C}, 81 \%$; b) $\mathrm{NaOMe}, \mathrm{MeOH}, 96 \%$; c) $\mathrm{tBu}_{2} \mathrm{Si}(\mathrm{OTf})_{2}$, Py, 94\%; d) TMSOTf, $\mathrm{CH}_{2} \mathrm{Cl}_{2}, 0^{\circ} \mathrm{C}, 80 \%$; e) (HF)n. $\mathrm{Py}, \mathrm{THF}, 0^{\circ} \mathrm{C}, 95 \%$; f) $\mathrm{SO}_{3} \cdot \mathrm{Me}_{3} \mathrm{~N}, \mathrm{DMF}, 100^{\circ} \mathrm{C}$, MW, 85\%; g) LiOH, $\mathrm{H}_{2} \mathrm{O}_{2}$, THF; $\mathrm{NaOH}, \mathrm{MeOH} / \mathrm{H}_{2} \mathrm{O} ; \mathrm{Ac}_{2} \mathrm{O}, \mathrm{Et}_{3} \mathrm{~N}, \mathrm{MeOH} / \mathrm{H}_{2} \mathrm{O}$, 73\%. TFA = trifluoroacetyl; TCA = trichloroacetimidoyl; Piv = pivaloyl; TMSOTf $=$ trimethylsilyl trifluoromethanesulfonate; $\mathrm{MW}=$ microwave.

Noteworthy, the $N$-trifluoroacetyl protecting group allowed the selective and high-yielding formation of the 1,2-trans glycosidic bond with the azido linker and, at the same time, it was easily removed at the end of the synthesis to reinstall the naturally occurring $\mathrm{N}$-acetyl moiety (see below). ${ }^{[5 \mathrm{~g}]}$ Hydrolysis of acetate esters under the classical Zemplen conditions followed by installation of a cyclic silylene acetal group at positions 4 and 6 using di-tert-butylsilyl triflate in pyridine gave compound $\mathbf{8}$, ready for elongation at the 3-OH position. Glycosylation with glucuronic acid donor 9 $^{\text {[12] }}$ using trimethyl silyl triflate as promoter afforded disaccharide $10 \mathrm{in} \mathrm{good} \mathrm{yield.} \mathrm{Treatment} \mathrm{with}(\mathrm{HF})_{n}$. Py complex in THF selectively released the $4-\mathrm{OH}$ and $6-\mathrm{OH}$ groups of the galactosamine unit that were subsequently sulfated, under microwave irradiation, ${ }^{[13]}$ by using sulfur trioxide trimethylamine. In these microwave-assisted reactions, 10 equiv. of sulfating reagent per $\mathrm{OH}$ are usually employed to ensure high yields and minimize the formation of partially sulfated compounds. Finally, basic hydrolysis followed by selective $\mathrm{N}$-acetylation provided azide-functionalized disaccharide 4 , containing the sulfate group distribution of the biologically active CS-E. Once the disaccharides 12 and 4 were prepared, we addressed the preparation of the corresponding CS glycodendrimers (Scheme 2). Three different cores, 13, 14 and 15, presenting 3, 4 and 6 alkyne groups respectively, were selected for the conjugation step in order to study the influence of valency on the molecular recognition of these multivalent systems. Compounds 13, 14 and 15 were prepared as previously described in the literature from commercially available starting materials. ${ }^{[14]}$ We first performed the $\mathrm{Cu}$ (I) catalyzed cycloaddition reaction between sulfated, fully protected disaccharide 12 and the dendritic cores. Global deprotection would afford the final water-soluble CS dendrimers. We envisioned that the use of 12, instead of the highly polar unprotected disaccharide $\mathbf{4}$, would facilitate the monitoring and the purification of the click chemistry reaction products. Thus, 12 was coupled to compound 13 using $\mathrm{CuSO}_{4}$ as copper source, sodium ascorbate to reduce in situ $\mathrm{Cu}$ (II) to $\mathrm{Cu}$ (I) and TBTA to stabilize $\mathrm{Cu}$ (I). Trivalent dendrimer 16 was obtained in good yield after microwave heating at $60^{\circ} \mathrm{C}$ for 45 min. The compound was purified by size exclusion chromatography (Sephadex LH-20) and remaining copper was removed by using a commercially available Quadrasil MP (mercaptopropyl) resin. The highly symmetric ${ }^{1} \mathrm{H}$ NMR spectrum showed the characteristic signal for the triazole proton at $\delta=$ $8.08 \mathrm{ppm}$ and the absence of the signals corresponding to the terminal alkynes of the starting material. In a similar way, 12 was conjugated to tetra- and hexavalent compounds 14 and 15 to provide the corresponding dendrimers 17 and 18 in good to excellent yields, after a first purification by Sephadex LH-20 followed by a silica gel chromatography. 
<smiles>C#CCOc1cc(OCC=C)cc(OCC=C)c1</smiles>

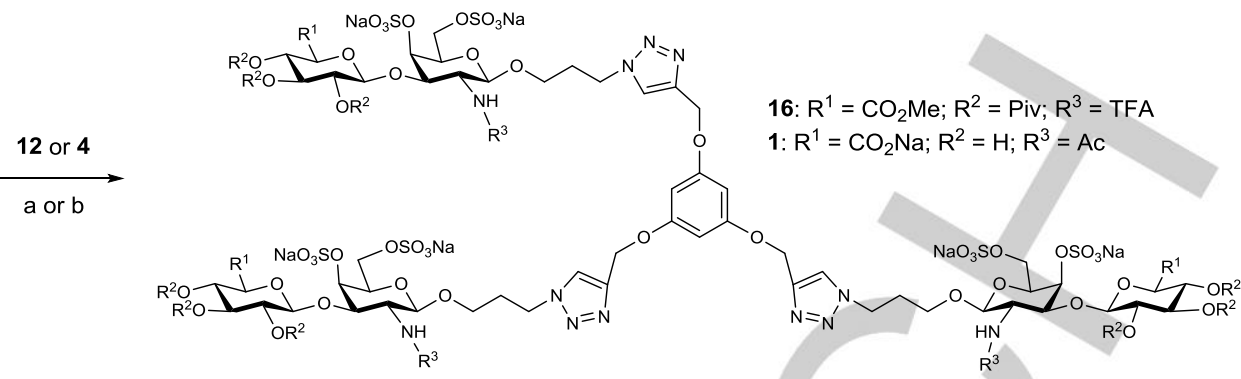<smiles>C#CCOCC(COCC#C)(COCC#C)COCC#C</smiles>

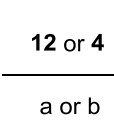<smiles>C#CCOCC(COCC#C)(COCC#C)COCC(COCC#C)(COCC#C)COCC#C</smiles>
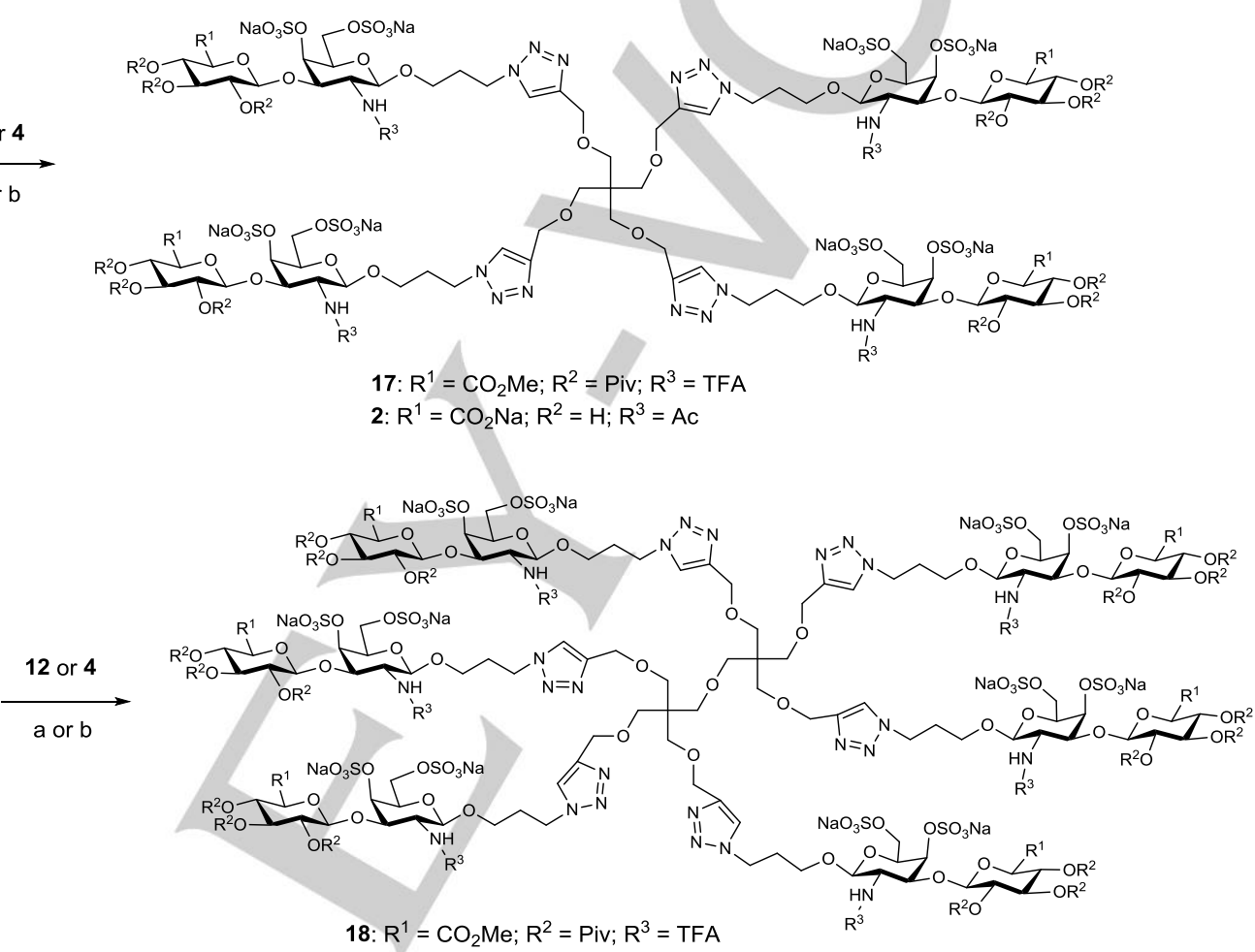

$\mathrm{NaO}_{3} \mathrm{SO} \quad \mathrm{OSO}_{3} \mathrm{Na}$

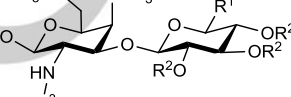

$a$ or $b$

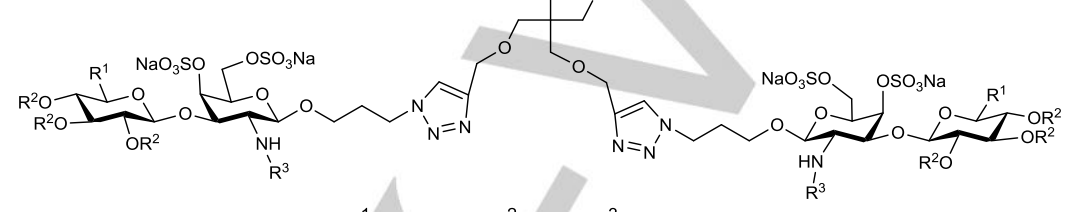

17: $\mathrm{R}^{1}=\mathrm{CO}_{2} \mathrm{Me} ; \mathrm{R}^{2}=\mathrm{Piv} ; \mathrm{R}^{3}=\mathrm{TFA}$

2: $\mathrm{R}^{1}=\mathrm{CO}_{2} \mathrm{Na} ; \mathrm{R}^{2}=\mathrm{H} ; \mathrm{R}^{3}=\mathrm{Ac}$

18: $\mathrm{R}^{1}=\mathrm{CO}_{2} \mathrm{Me} ; \mathrm{R}^{2}=$ Piv; $\mathrm{R}^{3}=\mathrm{TFA}$

3: $\mathrm{R}^{1}=\mathrm{CO}_{2} \mathrm{Na} ; \mathrm{R}^{2}=\mathrm{H} ; \mathrm{R}^{3}=\mathrm{Ac}$

Scheme 2. Reagents and conditions: a) $\mathrm{CuSO}_{4} \cdot 5 \mathrm{H}_{2} \mathrm{O}$, sodium ascorbate, TBTA, DMSO/ $\mathrm{H}_{2} \mathrm{O}, 60 \%$, $\mathrm{MW}, 45-50 \mathrm{~min}, 63 \%(\mathbf{1 6}), 62 \%$ (17), 85\% (18); b) $\mathrm{CuSO}_{4} \cdot 5 \mathrm{H}_{2} \mathrm{O}$, sodium ascorbate, TBTA, DMSO/PBS buffer, room temperature, overnight, quantitative (1), 90\% (2), quantitative (3). TBTA = tris[(1-benzyl-1H 1,2,3-triazol-4-yl)methyl]amine;

We next attempted the deprotection of CS dendrimer 16 by typical treatment with $\mathrm{H}_{2} \mathrm{O}_{2} / \mathrm{LiOH}$ and $\mathrm{NaOH},{ }^{[15]}$ followed by selective $\mathrm{N}$-acetylation of the unmasked amino functionality. Unexpectedly, this deprotection led to complex reaction mixtures where no pure fully deprotected CS dendrimer could be isolated. Here, it is worth to mention that the high polarity of this type of molecules, due to the presence of multiple sulfate and carboxylate negative charges, hampered both the monitoring and the purification of the reaction crudes.

To circumvent this problem, we explored an alternative strategy involving the direct conjugation of fully deprotected disaccharide
4. The copper mediated cycloaddition of such highly polar compounds can be considered as a challenging task, due to the presence in the sugar units of a large number of negative charges and free hydroxyl groups which could sequester the catalyst and prevent the cycloaddition reaction. However, we found that the reaction between fully deprotected sugar $\mathbf{4}$ and the dendritic core 13 provided easily the trivalent, water-soluble compound 1 in excellent yield. Best results were obtained when the reaction mixture was stirred at room temperature overnight, in the presence of $\mathrm{CuSO}_{4}$, TBTA and sodium ascorbate (approximately, 1, 2 and 3 equivalents per disaccharide ligand, respectively). The trivalent compound $\mathbf{1}$ was isolated as sodium 
salt by simple elution from Sephadex $\mathrm{LH}-20$ and Dowex $\mathrm{Na}^{+}$ columns. Similar results were observed in the coupling of $\mathbf{4}$ with the tetra- and hexavalent scaffolds $\mathbf{1 4}$ and $\mathbf{1 5}$. In this way, dendrimers 2 and 3, displaying four and six copies of the CS-E disaccharide ligand, respectively, were obtained in excellent yields as well. All these molecules were fully characterized by NMR spectroscopy.

Once the tri-, tetra- and hexavalent CS-ligand dendrimers were prepared, we investigated whether the multivalent presentation of CS-E disaccharides on dendrimers could increase their binding affinity for protein receptors. In particular, we examined the interaction between our CS-E glycodendrimers and midkine. This heparin-binding growth factor is implicated in diverse biological processes such as angiogenesis, neurogenesis and tumorigenesis and there is a great interest in the discovery of new high-affinity midkine ligands that could modulate its activity. ${ }^{[16]}$ Several studies have demonstrated that midkine interact with CS-E polysaccharide chains in the nanomolar range and a tetrasaccharide is the minimum oligosaccharide length for significant protein recognition. ${ }^{[4 a, 11,17]}$

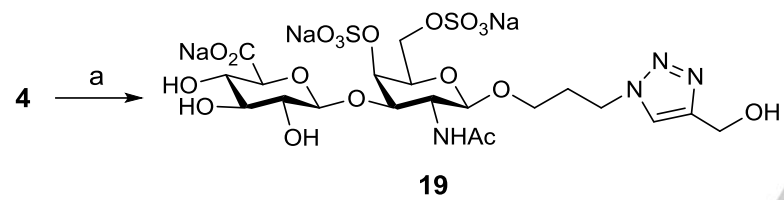

Scheme 3. Reagents and conditions: a) Propargyl alcohol, $\mathrm{CuSO}_{4} \cdot 5 \mathrm{H}_{2} \mathrm{O}$, sodium ascorbate, TBTA, DMSO/PBS buffer, room temperature, overnight, quantitative.

To measure the relative binding affinities of the synthesized glycodendrimers for midkine, we employed a competition fluorescence polarization (FP) assay, previously developed in our lab. ${ }^{[11,17 b, 18]} \mathrm{FP}$ technique is a powerful tool for the study of biomolecular interactions in solution. It is based on the fact that emitted light polarization depends on the rotational rate/molecular weight of a fluorescent molecule. Therefore, high molecular weight complexes formed by a fluorescent sugar (fluorescent probe) and a protein are characterized by high polarization values. The addition of an inhibitor that is able to displace the fluorescent carbohydrate from the complex results in a concentration-dependent polarization decrease. In our competition experiment, we measured the FP of microplate wells containing fixed amounts of midkine and a fluorescent probe (a fluorescein labelled heparin-like hexasaccharide previously prepared in our lab ${ }^{[18]}$ ) in the presence of increasing concentrations of our dendrimers (Figure 1). The inhibition curves showed a reduction in the FP value, indicating that CS-E dendrimers interact with midkine. Mathematical fitting provided $\mathrm{IC}_{50}$ values, defined as dendrimer concentration required for $50 \%$ inhibition (Table 1). Our results indicated a strong interaction between midkine and glycodendrimers $\mathbf{1 - 3}$, with $\mathrm{IC}_{50}$ values in the low micromolar range.

Next, we compared these relative binding affinities with that corresponding to the monovalent ligand. CS-E disaccharide 4 did not display significant binding to midkine at $250 \mu \mathrm{M}$ concentration, which is in agreement with previous reports showing no relevant interaction between disaccharides and CS binding proteins. $\left..^{[9 b}, 11,17 \mathrm{~b}\right]$ On the other hand, it has been demonstrated that the presence of aromatic ring-containing protecting groups on CS oligosaccharide structures enhances their binding to midkine. ${ }^{[11,17 b]}$ For this reason, we consider CS-E disaccharide 19 (Scheme 3) as a more appropriate monovalent ligand than $\mathbf{4}$ for comparison purposes in order to take into account any effect coming from the triazole rings of the glycodendrimers. Compound $\mathbf{1 9}$ was easily prepared by cycloaddition of $\mathbf{4}$ and the commercially available propargyl alcohol (Scheme 3).

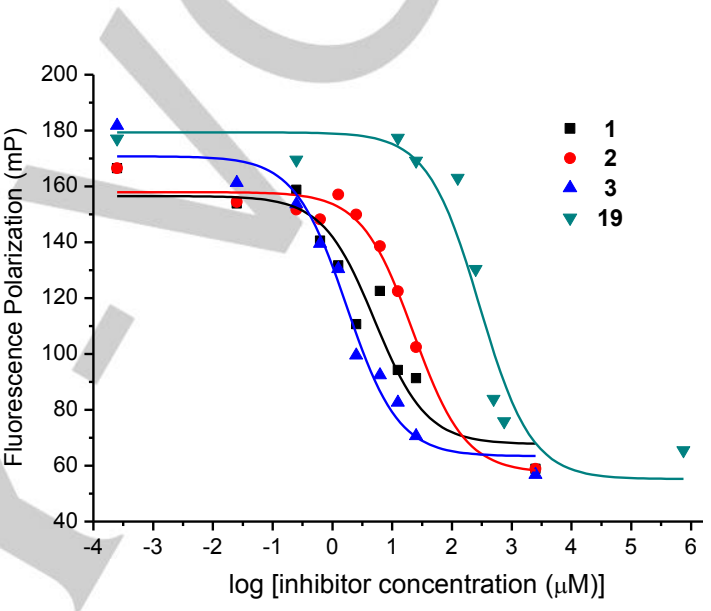

Figure 1. Representative competition curves showing the ability of compounds 19, and 1-3 to inhibit the interaction between midkine and the fluorescent probe. The fluorescence polarization of samples containing midkine (63 nM), fluorescent probe $(10 \mathrm{nM})$ and increasing concentrations of inhibitors were measured and the resulting curves were fitted to the equation for a one-site competitive interaction model in order to calculate the $\mathrm{IC}_{50}$ values. All the polarization values are the average of three replicate wells. At least three independent experiments were carried out for each $\mathrm{IC}_{50}$ calculation.

The FP competition assay afforded an $\mathrm{IC}_{50}=305 \mu \mathrm{M}$ for 19 , a binding affinity significantly lower than those displayed by the multivalent structures (Table 1).

Table 1. $I_{50}$ values for synthetic glycodendrimers 1-3 and monovalent reference compound 19 obtained in fluorescence polarization midkine competition assays.

\begin{tabular}{lcccc}
\hline Compound & $\mathbf{1}$ & $\mathbf{2}$ & $\mathbf{3}$ & $\mathbf{1 9}$ \\
\hline $\mathrm{IC}_{50}(\mu \mathrm{M})^{[\mathrm{a}]}$ & $3.9 \pm 1.4$ & $15.0 \pm 5.6$ & $1.2 \pm 0.6$ & $305 \pm 22$ \\
$\mathrm{RIP}^{[\mathrm{b}]}$ & 26 & 5 & 42 & 1 \\
\hline
\end{tabular}

[a] Errors represent standard deviations from at least three independent experiments. [b] Relative inhibitory potency (RIP) calculated as $\left(\mathrm{IC}_{50}\right)_{\text {monovalent }}$ ${ }_{19} /\left(\mathrm{IC}_{50} \times\right.$ valency $)$.

Trivalent 1, tetravalent 2 and hexavalent 3 glycodendrimers showed relative inhibitory potencies (RIP) per sugar unit of 26,5 
and 42 , respectively, indicating that both the valency and the nature of the dendritic core may influence on the activity of these compounds. Interestingly, compound $\mathbf{1}$ containing three copies of CS disaccharide displayed significantly higher inhibitory activity than dendrimer $\mathbf{2}$ with four ligand copies. We speculate that the presence of the central phenyl aromatic ring in dendrimer 1, and the spatial arrangement imposed by this dendritic core, favours the molecular recognition of this trivalent derivative by midkine. Overall, these results demonstrate that the presentation of CS-E disaccharide ligands on dendritic scaffolds strongly increase their interaction with midkine due to the multivalent effect.

\section{Conclusions}

GAG is a large family of polydisperse polysaccharides with a different grade and pattern of sulfation. The sequence consists of a repeated disaccharide which is the main epitope. However, these disaccharides are not big enough to interact efficiently with the corresponding receptor. At least oligosaccharides with 4 to 6 carbohydrate units are required to observe reasonable affinities. Taking into account the complexity of the GAG synthesis, new strategies have to be developed. Multivalency is a very attractive approach to improve remarkably the affinity of carbohydrates. It is reasonable to think that the conjugation of several copies of GAG disaccharide units to a multivalent scaffold could provide compounds with good binding affinities to their corresponding receptors. Chondroitin Sulfate-E is a class of GAGs with the repeated unit GIcAGalNAc (4,6-di-OSO 3 ). CS is involved in several biological events and the development of tools comprising this GAG is a topic of tremendous interest. In this work, we have shown the synthesis of the conserved disaccharide unit of the CS-E conveniently functionalized at the reductive end with a short linker with a terminal azido group. Using the $\mathrm{Cu}(\mathrm{I})$ catalyzed alkyne azide cycloaddition (CuAAC) reaction, multivalent systems have been created using this disaccharide and simple small dendritic cores with the aim to increase the binding affinities to the growth factor midkine. Using fluorescence polarization assays, we have demonstrated that the disaccharide itself present a very low affinity for this cytokine; however, when this disaccharide is conjugated to dendritic scaffolds, even using a low valency, the binding affinity is remarkable increased to the low micromolar range (for the system with 6 copies of the ligand) confirming the initial assumption. New research is being performed in the group in order to study the interactions that drive the formation of the complexes.

In summary, we have demonstrated that this multivalent approach using relative simple disaccharides as ligands is a good strategy to develop new glycomimetics to study those processes implying CS-E. In fact, this strategy could be easily extrapolated to other members of the GAG family and other
GAG receptors, being a very interesting approach to explore binding affinities and selectivity of these types of carbohydrates.

\section{Experimental Section}

General synthetic procedures: Thin layer chromatography (TLC) analyses were performed on silica gel $60 \mathrm{~F}_{254}$ precoated on aluminium plates (Merck) and the compounds were detected by staining with sulfuric acid/ethanol (1:9), with cerium (IV) sulfate (10 $\mathrm{g}) /$ phosphomolybdic acid $(13 \mathrm{~g}) /$ sulfuric acid $(60 \mathrm{~mL})$ solution in water (1 $\mathrm{L}$ ), or with anisaldehyde solution [anisaldehyde $(25 \mathrm{~mL})$ with sulfuric acid $(25 \mathrm{~mL})$, ethanol $(450 \mathrm{~mL})$ and acetic acid $(1 \mathrm{~mL})]$, followed by heating at over $200^{\circ} \mathrm{C}$. Column chromatography was carried out on silica gel 60 (0.2-0.5 mm, 0.2-0.063 mm or 0.040-0.015 mm; Merck). Optical rotations were determined with a Perkin-Elmer 341 polarimeter. ${ }^{1} \mathrm{H}$ - and ${ }^{13} \mathrm{C}-\mathrm{NMR}$ spectra were acquired on Bruker DPX-300, Avance III-400 and DRX-500 spectrometers. Electrospray mass spectra (ESI MS) were carried out with an Esquire $6000 \mathrm{ESI}$-Ion Trap from Bruker Daltonics. High resolution mass spectra (HR MS) were carried out by CITIUS (Universidad de Sevilla). MALDI-TOF mass spectra (MALDI-TOF MS) were carried out with a microflex instrument from Bruker. Microwave-based reactions were performed using a Biotage Initiator Eight synthesizer in sealed reaction vessels.

3-Azidopropyl 3,4,6-tri-O-acetyl-2-deoxy-2-trifluoroacetamido- $\beta$-Dgalactopyranoside (6): Donor 5 (815 mg, $1.49 \mathrm{mmol}$ ) was coevaporated with toluene, dried under vacuum and then dissolved in dry $\mathrm{CH}_{2} \mathrm{Cl}_{2}(8$ $\mathrm{mL})$ in the presence of freshly activated $4 \AA$ molecular sieves. 3azidopropanol $(207 \mu \mathrm{L}, 2.24 \mathrm{mmol})$ was added and the mixture was stirred for $10 \mathrm{~min}$. TMSOTf $(54 \mu \mathrm{L}, 0.30 \mathrm{mmol})$ was added at $0^{\circ} \mathrm{C}$. After stirring for $15 \mathrm{~min}$ at $0^{\circ} \mathrm{C}$, the reaction mixture was neutralized with $\mathrm{Et}_{3} \mathrm{~N}$, filtered and concentrated to dryness. The residue was purified by column chromatography (hexane-EtOAc 2:1) to afford 6 (585 mg, 81\%). TLC (hexane-EtOAc 2:1) Rf 0.23; [a $]^{20} \mathrm{D}-14^{\circ}\left(\mathrm{c} 1.0, \mathrm{CHCl}_{3}\right) ;{ }^{1} \mathrm{H}-\mathrm{NMR}(300$ $\left.\mathrm{MHz}, \mathrm{CDCl}_{3}\right): \delta 6.91\left(\mathrm{~d}, 1 \mathrm{H}, \mathrm{J}_{\mathrm{NH}, 2}=8.1 \mathrm{~Hz}, \mathrm{NH}\right), 5.37\left(\mathrm{~d}, 1 \mathrm{H}, J_{3,4}=3.0\right.$ $\mathrm{Hz}, \mathrm{H}-4), 5.22$ (dd, $\left.1 \mathrm{H}, \mathrm{J}_{2,3}=11.4 \mathrm{~Hz}, \mathrm{H}-3\right), 4.62\left(\mathrm{~d}, 1 \mathrm{H}, \mathrm{J}_{1,2}=8.4 \mathrm{~Hz}, \mathrm{H}-\right.$ 1), 4.23-3.93 (m, 5H, H-2, H-5, H-6a, H-6b, $\left.\mathrm{CH}_{2}\right), 3.57\left(\mathrm{~m}, 1 \mathrm{H}, \mathrm{CH}_{2}\right), 3.35$ $\left(\mathrm{m}, 2 \mathrm{H}, \mathrm{CH}_{2}\right), 2.16,2.05,1.99$ (3s, 9H, OAc), $1.84\left(\mathrm{~m}, 2 \mathrm{H}, \mathrm{CH}_{2}\right)$; ${ }^{13} \mathrm{C}-\mathrm{NMR}\left(75 \mathrm{MHz}, \mathrm{CDCl}_{3}\right): \delta 170.8,170.6,170.3$ (3CO), 157.5 (q, $\left.\mathrm{COCF}_{3}\right), 115.6\left(\mathrm{q}, \mathrm{COCF}_{3}\right), 100.7(\mathrm{C}-1), 70.9(\mathrm{C}-5), 69.6(\mathrm{C}-3), 66.6$, $66.5\left(\mathrm{C}-4, \mathrm{CH}_{2}\right), 61.5(\mathrm{C}-6), 51.6(\mathrm{C}-2), 47.9\left(\mathrm{CH}_{2}\right), 28.9\left(\mathrm{CH}_{2}\right), 20.7$, 20.6, $20.4\left(3 \mathrm{CH}_{3}\right)$; HR MS: $\mathrm{m} / \mathrm{z}$ : calcd for $\mathrm{C}_{17} \mathrm{H}_{23} \mathrm{~F}_{3} \mathrm{~N}_{4} \mathrm{O}_{9} \mathrm{Na}$ : 507.1309; found: $507.1312[\mathrm{M}+\mathrm{Na}]^{+}$.

\section{3-Azidopropyl}

4,6-O-di-tert-butylsilylene-2-deoxy-2trifluoroacetamido- $\beta$-D-galactopyranoside (8): Compound 6 (325 mg, $0.67 \mathrm{mmol}$ ) was dissolved in $\mathrm{MeOH}(3 \mathrm{~mL})$, and $\mathrm{NaOMe}(47 \mu \mathrm{L}$ of a 2.17 $\mathrm{M}$ solution in $\mathrm{MeOH}$ ) was added. After 45 min, Amberlite acidic resin was added until $\mathrm{pH} 7$. The Amberlite resin was filtered off, and the solvent was removed in vacuo to give $7(231 \mathrm{mg}, 96 \%)$ that was directly used in the next step without further purification. TLC $\left(\mathrm{CH}_{2} \mathrm{Cl}_{2}-\mathrm{MeOH}\right.$ 8:1) Rf 0.36 .

Compound 7 (333 mg, $0.93 \mathrm{mmol})$ was dissolved in dry Py $(17 \mathrm{~mL})$ and cooled $\left(0^{\circ} \mathrm{C}\right)$. Di-tert-butylsilyl bis(trifluoromethanesulfonate) $(0.33 \mathrm{~mL}$, $1.0 \mathrm{mmol}$ ) was added and the mixture was stirred at room temperature for $15 \mathrm{~min}$. The reaction was quenched with $\mathrm{MeOH}(1.5 \mathrm{~mL})$, diluted with EtOAc $(100 \mathrm{~mL})$, and washed with $1 \mathrm{M} \mathrm{HCl}$, saturated aqueous $\mathrm{NaHCO}_{3}$, and $\mathrm{H}_{2} \mathrm{O}$. The organic phase was dried $\left(\mathrm{MgSO}_{4}\right)$, filtered and concentrated to dryness. The residue was purified by column chromatography (hexane-EtOAc 3:1) to afford 8 as a white foam (435 $\mathrm{mg}, 94 \%)$. TLC (toluene- EtOAc 6:1) Rf 0.18; [ $\alpha]^{20} \mathrm{D}+13^{\circ}\left(c 1.0, \mathrm{CHCl}_{3}\right)$; ${ }^{1} \mathrm{H}-\mathrm{NMR}\left(300 \mathrm{MHz}, \mathrm{CDCl}_{3}\right): \delta 6.85\left(\mathrm{~d}, 1 \mathrm{H}, \mathrm{J}_{\mathrm{NH}, 2}=8.5 \mathrm{~Hz}, \mathrm{NH}\right), 4.53(\mathrm{~d}$, 
$\left.1 \mathrm{H}, J_{1,2}=8.1 \mathrm{~Hz}, \mathrm{H}-1\right), 4.38\left(\mathrm{~d}, 1 \mathrm{H}, J_{3,4}=3.0 \mathrm{~Hz}, \mathrm{H}-4\right), 4.26(\mathrm{~m}, 2 \mathrm{H}, \mathrm{H}-6)$, 3.97-3.88 (m, 2H, H-2, $\left.\mathrm{CH}_{2}\right), 3.76\left(\mathrm{dd}, 1 \mathrm{H}, \mathrm{J}_{2,3}=10.5 \mathrm{~Hz}, \mathrm{H}-3\right), 3.54(\mathrm{~m}$, $1 \mathrm{H}, \mathrm{CH}_{2}$ ), 3.44 (br s, $\left.1 \mathrm{H}, \mathrm{H}-5\right), 3.33$ (t, $\left.2 \mathrm{H}, \mathrm{CH}_{2}\right), 1.80\left(\mathrm{~m}, 2 \mathrm{H}, \mathrm{CH}_{2}\right.$ ), 1.05, $1.04\left(2 \mathrm{~s}, 18 \mathrm{H}, \mathrm{C}\left(\mathrm{CH}_{3}\right)_{3}\right) ;{ }^{13} \mathrm{C}-\mathrm{NMR}\left(75 \mathrm{MHz}, \mathrm{CDCl}_{3}\right): \delta 158.0$ (q, J $\mathrm{C}, \mathrm{F}$ $\left.=37.6 \mathrm{~Hz}, \mathrm{COCF}_{3}\right), 115.8$ (q, JC,F $\left.=287.3 \mathrm{~Hz}, \mathrm{COCF}_{3}\right), 100.0(\mathrm{C}-1), 72.0$ (C-4), 71.3 (C-5), 71.0 (C-3), 66.8 (C-6), $65.9\left(\mathrm{CH}_{2}\right), 54.6$ (C-2), 48.0

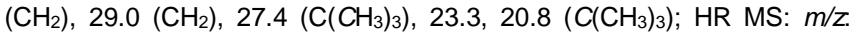
calcd for $\mathrm{C}_{19} \mathrm{H}_{33} \mathrm{~F}_{3} \mathrm{~N}_{4} \mathrm{O}_{6} \mathrm{NaSi}$ : 521.2014; found: 521.2019 [M+Na] ${ }^{+}$

\section{3-Azidopropyl 3-O-(methyl 2,3,4-tri-O-pivaloyl- $\beta$ - glucopyranosyluronate)-4,6- $O$-di-tert-butylsilylene-2-deoxy-2-} trifluoroacetamido- $\beta$-D-galactopyranoside (10) Donor 9 (111 mg, $0.184 \mathrm{mmol}$ ) and aceptor $8(61 \mathrm{mg}, 0.122 \mathrm{mmol})$ were coevaporated with toluene, concentrated in vacuo and dissolved in dry $\mathrm{CH}_{2} \mathrm{Cl}_{2}(1.5 \mathrm{~mL})$ in the presence of freshly activated $4 \AA$ molecular sieves $(110 \mathrm{mg})$. After stirring for $15 \mathrm{~min}$ at $0{ }^{\circ} \mathrm{C}$, TMSOTf $(100 \mu \mathrm{L}$ of a $0.18 \mathrm{M}$ solution in dry $\mathrm{CH}_{2} \mathrm{Cl}_{2}$ ) was added under an argon atmosphere. After stirring for $30 \mathrm{~min}$ at $0^{\circ} \mathrm{C}$, the reaction mixture was neutralized with $\mathrm{Et}_{3} \mathrm{~N}$, filtered, and concentrated to dryness. The residue was purified by column chromatography (toluene-acetone 18:1) to afford $\mathbf{1 0}$ as colorless oil (92 $\mathrm{mg}, 80 \%$ ). TLC (toluene-acetone 18:1) Rf 0.29; [a] ${ }^{20} \mathrm{D}+10^{\circ}$ (c 1.0, $\left.\mathrm{CHCl}_{3}\right) ;{ }^{1} \mathrm{H}-\mathrm{NMR}\left(500 \mathrm{MHz}, \mathrm{CDCl}_{3}\right): \delta 7.17\left(\mathrm{~d}, 1 \mathrm{H}, J_{2, \mathrm{NH}}=6.8 \mathrm{~Hz}, \mathrm{NH}\right)$, $5.34\left(\mathrm{~d}, 1 \mathrm{H}, J_{1,2}=7.8 \mathrm{~Hz}, \mathrm{H}^{\prime}{ }^{\prime}\right), 5.27\left(\mathrm{t}, 1 \mathrm{H}, J_{2,3}=J_{3,4}=9.3 \mathrm{~Hz}, \mathrm{H}-3^{\prime}\right.$ ), $5.20\left(\mathrm{t}, 1 \mathrm{H}, J_{3,4}=J_{4,5}=9.6 \mathrm{~Hz}, \mathrm{H}-4^{\prime}\right), 5.05-5.00\left(\mathrm{~m}, 2 \mathrm{H}, \mathrm{H}-2^{\prime}, \mathrm{H}-1\right), 4.65$ (d, $\left.1 \mathrm{H}, J_{3,4}=2.4 \mathrm{~Hz}, \mathrm{H}-4\right), 4.43\left(\mathrm{dd}, 1 \mathrm{H}, J_{2,3}=11.4 \mathrm{~Hz}, \mathrm{H}-3\right.$ ), 4.26 (2dd, $2 \mathrm{H}, \mathrm{H}-6), 3.98\left(\mathrm{~d}, 1 \mathrm{H}, \mathrm{H}-5^{\prime}\right), 3.90\left(\mathrm{~m}, 1 \mathrm{H}, \mathrm{CH}_{2}\right), 3.80(\mathrm{~m}, 1 \mathrm{H}, \mathrm{H}-2), 3.73$ (s, $\left.3 \mathrm{H}, \mathrm{CO}_{2} \mathrm{Me}\right), 3.60\left(\mathrm{~m}, 1 \mathrm{H}, \mathrm{CH}_{2}\right), 3.45(\mathrm{br} \mathrm{s}, 1 \mathrm{H}, \mathrm{H}-5), 3.35(\mathrm{~m}, 2 \mathrm{H}$, $\left.\mathrm{CH}_{2}\right), 1.82\left(\mathrm{~m}, 2 \mathrm{H}, \mathrm{CH}_{2}\right), 1.15-1.08\left(5 \mathrm{~s}, 45 \mathrm{H}, \mathrm{C}\left(\mathrm{CH}_{3}\right) 3\right) ;{ }^{13} \mathrm{C}-\mathrm{NMR}(100$ $\left.\mathrm{MHz}, \mathrm{CDCl}_{3}\right): \delta 177.0,176.6,176.3,167.4(4 \times \mathrm{CO}), 157.7$ (q, $\left.\mathrm{COCF}_{3}\right)$, 115.6 (q, $\left.\mathrm{COCF}_{3}\right), 99.0,98.9$ (C-1, C-1'), 74.2, 74.0 (C-3, C-4), 72.0, 71.9 (C-5', C-3'), 71.3, 71.0 (C-2', C-5), 69.0 (C-4'), 67.0 (C-6), $66.5\left(\mathrm{CH}_{2}\right)$, 54.5 (C-2), $52.9\left(\mathrm{CO}_{2} \mathrm{Me}\right), 48.2\left(\mathrm{CH}_{2}\right), 38.7\left(\mathrm{C}_{\left.\left(\mathrm{CH}_{3}\right)_{3}\right),} 29.1\left(\mathrm{CH}_{2}\right), 27.5-\right.$ $27.0\left(\mathrm{C}\left(\mathrm{CH}_{3}\right)_{3}\right), \quad 23.3,20.7\left(\mathrm{C}_{\left.\left(\mathrm{CH}_{3}\right)_{3}\right) ;}\right.$ HR MS: $\mathrm{m} / \mathrm{z}$ : calcd for $\mathrm{C}_{41} \mathrm{H}_{67} \mathrm{~F}_{3} \mathrm{~N}_{4} \mathrm{O}_{15} \mathrm{NaSi}$ : 963.4216 ; found: $963.4175[\mathrm{M}+\mathrm{Na}]^{+}$.

\section{3-Azidopropyl 3-O-(methyl 2,3,4-tri-O-pivaloyl- $\beta$-D- glucopyranosyluronate)-2-deoxy-2-trifluoroacetamido- $\beta$-D- galactopyranoside (11) An excess of $(\mathrm{HF})_{\mathrm{n}} \cdot \mathrm{Py}(409 \mu \mathrm{L}, 15.7 \mathrm{mmol})$ was added at $0^{\circ} \mathrm{C}$ under an argon atmosphere to a solution of $10(74 \mathrm{mg}$, $0.079 \mathrm{mmol})$ in dry THF $(2.0 \mathrm{~mL})$. After $20 \mathrm{~h}$ at $0^{\circ} \mathrm{C}$ the mixture was diluted with $\mathrm{CH}_{2} \mathrm{Cl}_{2}$ and washed with $\mathrm{H}_{2} \mathrm{O}$ and saturated $\mathrm{NaHCO}_{3}$ solution until neutral $\mathrm{pH}$. The organic layers were dried $\left(\mathrm{MgSO}_{4}\right)$, filtered and concentrated in vacuo to give $11(60 \mathrm{mg}, 95 \%)$ as a white amorphous solid. TLC (hexane-EtOAc 2:3) Rf 0.20; [a] ${ }^{20} \mathrm{D}-17^{\circ}$ (c 1.0, $\mathrm{MeOH}$ ); ${ }^{1} \mathrm{H}-\mathrm{NMR}\left(400 \mathrm{MHz}, \mathrm{CDCl}_{3} / \mathrm{CD}_{3} \mathrm{OD} 5: 1\right): \delta 5.31\left(\mathrm{t}, 1 \mathrm{H}, J_{2,3}=J_{3,4}=\right.$ $\left.9.3 \mathrm{~Hz}, \mathrm{H}-3^{\prime}\right), 5.16\left(\mathrm{t}, 1 \mathrm{H}, \mathrm{H}-4^{\prime}\right), 5.02\left(\mathrm{dd}, 1 \mathrm{H}, \mathrm{H}^{\prime} \mathbf{2}^{\prime}\right), 4.82$ (d, 1H, J1,2 = 7.7 $\left.\mathrm{Hz}, \mathrm{H}-1^{\prime}\right), 4.47\left(\mathrm{~d}, 1 \mathrm{H}, \mathrm{J}_{1,2}=8.3 \mathrm{~Hz}, \mathrm{H}-1\right), 4.16\left(\mathrm{dd}, 1 \mathrm{H}, \mathrm{J}_{2,3}=10.9 \mathrm{~Hz}\right.$, $\left.J_{3,4}=3.0 \mathrm{~Hz}, \mathrm{H}-3\right), 4.12\left(\mathrm{~d}, 1 \mathrm{H}, J_{4,5}=10.0 \mathrm{~Hz}, \mathrm{H}-5^{\prime}\right), 4.04(\mathrm{~m}, 1 \mathrm{H}, \mathrm{H}-4)$, 3.95-3.89 (m, 2H, H-2, $\left.\mathrm{CH}_{2}\right), 3.83-3.71\left(\mathrm{~m}, 5 \mathrm{H}, 2 \times \mathrm{H}-6, \mathrm{CO}_{2} \mathrm{Me}\right), 3.54-$ $3.48\left(\mathrm{~m}, 2 \mathrm{H}, \mathrm{H}-5, \mathrm{CH}_{2}\right), 3.35-3.31\left(\mathrm{~m}, 2 \mathrm{H}, \mathrm{CH}_{2}\right), 1.78\left(\mathrm{~m}, 2 \mathrm{H}, \mathrm{CH}_{2}\right), 1.12-$ 1.09 (3s, $\left.27 \mathrm{H}, \mathrm{C}\left(\mathrm{CH}_{3}\right)_{3}\right) ;{ }^{13} \mathrm{C}-\mathrm{NMR}\left(100 \mathrm{MHz}, \mathrm{CDCl}_{3} / \mathrm{CD}_{3} \mathrm{OD}\right.$ 5:1): $\delta$ 177.6, 177.2, 177.0, 167.8 (4 x CO), $158.0\left(\mathrm{q}, \mathrm{COCF}_{3}\right), 115.8$ (q, $\mathrm{COCF}_{3}$ ), 100.5 (C-1), 99.9 (C-1'), 76.1 (C-3), 74.5 (C-5), 72.1 (C-5'), 71.6 (C-3'), 71.0 (C-2'), 69.3 (C-4'), $68.1(\mathrm{C}-4), 66.1\left(\mathrm{CH}_{2}\right), 61.4(\mathrm{C}-6), 52.8$, $52.7\left(\mathrm{Me}\left(\mathrm{CO}_{2} \mathrm{Me}\right), \mathrm{C}-2\right), 47.9\left(\mathrm{CH}_{2}\right), 38.7\left(\mathrm{C}_{\left.\left(\mathrm{CH}_{3}\right)_{3}\right),} 28.9\left(\mathrm{CH}_{2}\right), 26.9-\right.$ $26.7\left(\mathrm{C}_{(}\left(\mathrm{CH}_{3}\right)_{3}\right)$; HR MS: $\mathrm{m} / \mathrm{z}$ : calcd for $\mathrm{C}_{33} \mathrm{H}_{51} \mathrm{~F}_{3} \mathrm{~N}_{4} \mathrm{O}_{15} \mathrm{Na}$ : 823.3195; found: $823.3191[\mathrm{M}+\mathrm{Na}]^{+}$.}

\section{3-Azidopropyl} 3-O-(methyl

2,3,4-tri-O-pivaloyl- $\beta$-Dglucopyranosyluronate)-2-deoxy-4,6-di-O-sulfo-2-

trifluoroacetamido- $\beta$-D-galactopyranoside (12) Compound 11 (90 mg, $0.11 \mathrm{mmol}$ ) and sulfur trioxide-trimethylamine complex $(313 \mathrm{mg}, 2.25$ $\mathrm{mmol})$ were dissolved in dry DMF $(6.0 \mathrm{~mL})$ and heated at $100^{\circ} \mathrm{C}$ for 30 min using microwave radiation ( $20 \mathrm{~W}$ average power). The reaction vessel was cooled and $\mathrm{Et}_{3} \mathrm{~N}(500 \mu \mathrm{L}), \mathrm{MeOH}(1 \mathrm{~mL})$ and $\mathrm{CH}_{2} \mathrm{Cl}_{2}(1 \mathrm{~mL})$ were added. The solution was purified by Sephadex $\mathrm{LH} 20\left(\mathrm{CH}_{2} \mathrm{Cl}_{2}\right.$ $\mathrm{MeOH} \mathrm{1:1)} \mathrm{to} \mathrm{obtain} 12$ as triethylammonium salt. Further elution from a column of Dowex $50 \mathrm{WX} 4-\mathrm{Na}^{+}\left(\mathrm{MeOH} / \mathrm{H}_{2} \mathrm{O}\right.$ 9:1) afforded 12 as sodium salt $(96 \mathrm{mg}, 85 \%)$. TLC (EtOAc/pyridine/ $\mathrm{H}_{2} \mathrm{O} / \mathrm{AcOH}$ 15:5:3:1) Rf 0.30; $[\mathrm{a}]^{20 \mathrm{D}}-9^{\circ}(\mathrm{c} 1.0, \mathrm{MeOH}) ;{ }^{1} \mathrm{H}-\mathrm{NMR}\left(400 \mathrm{MHz}, \mathrm{CD}_{3} \mathrm{OD}\right): \delta$ 5.38-5.31 (m, $\left.2 \mathrm{H}, \mathrm{H}-3^{\prime}, \mathrm{H}-4^{\prime}\right), 5.22-5.16\left(\mathrm{~m}, 1 \mathrm{H}, \mathrm{H}-2^{\prime}\right), 4.99-4.95\left(\mathrm{~m}, 2 \mathrm{H}, \mathrm{H}-1^{\prime}, \mathrm{H}-4\right)$ 4.50-4.41 (m, 2H, H-1, H-6a), 4.30-4.22 (m, 2H, H-5, H-6b), 4.19-4.06 ( $\mathrm{m}, 2 \mathrm{H}, \mathrm{H}-2, \mathrm{H}-3), 4.02-3.93\left(\mathrm{~m}, 2 \mathrm{H}, \mathrm{H}-5, \mathrm{CH}_{2}\right.$ ), 3.77 (s, 3H, CO $\left.2 \mathrm{Me}\right)$, 3.62-3.54 (m, $\left.1 \mathrm{H}, \mathrm{CH}_{2}\right), 3.37\left(\mathrm{~m}, 2 \mathrm{H}, \mathrm{CH}_{2}\right), 1.90-1.73\left(\mathrm{~m}, 2 \mathrm{H}, \mathrm{CH}_{2}\right), 1.18-$ $1.10\left(2 \mathrm{~s}, 27 \mathrm{H}, \mathrm{C}\left(\mathrm{CH}_{3}\right)_{3}\right) ;{ }^{13} \mathrm{C}-\mathrm{NMR}(100 \mathrm{MHz}$, selected data obtained from HSQC experiment, $\mathrm{CD}_{3} \mathrm{OD}$ ): $\delta 101.2$ (C-1), 100.3 (C-1'), 75.3 (C-4), 74.4 (C-3), 72.9 (C-5), 72.5 (C-3'), 71.9 (C-5'), 71.4 (C-2'), 69.5 (C-4'), $67.6(\mathrm{C}-6), 65.9\left(\mathrm{CH}_{2}\right), 52.5(\mathrm{C}-2), 52.0\left(\mathrm{Me}\left(\mathrm{CO}_{2} \mathrm{Me}\right)\right), 47.7\left(\mathrm{CH}_{2}\right), 28.8$ $\left(\mathrm{CH}_{2}\right)$, 26.0-26.6 $\left(\mathrm{C}\left(\mathrm{CH}_{3}\right)_{3}\right)$; ESI MS: $m / z$ : calcd for $\mathrm{C}_{33} \mathrm{H}_{50} \mathrm{~F}_{3} \mathrm{~N}_{4} \mathrm{O}_{21} \mathrm{~S}_{2}$ : 959.2; found: $959.2[\mathrm{M}-2 \mathrm{Na}+\mathrm{H}]$.

3-Azidopropyl 3-O-( $\beta$-D-glucopyranosyluronic acid)-2-acetamido-2deoxy-4,6-di-O-sulfo- $\beta$-D-galactopyranoside (4) $\mathrm{H}_{2} \mathrm{O}_{2}(30 \%, 0.18 \mathrm{~mL})$ and an aqueous solution of $\mathrm{LiOH}(0.7 \mathrm{M}, 0.22 \mathrm{~mL})$ were added at $-5^{\circ} \mathrm{C}$ to a solution of $12(21 \mathrm{mg}, 18 \mu \mathrm{mol}$, triethylammonium salt) in THF (1 mL). After stirring for $24 \mathrm{~h}$ at room temperature, $\mathrm{MeOH}(1.9 \mathrm{~mL}), \mathrm{H}_{2} \mathrm{O}(0.57$ $\mathrm{mL}$ ) and an aqueous solution of $\mathrm{NaOH}(4 \mathrm{M}, 0.45 \mathrm{~mL}$ ) were added. After stirring for $36 \mathrm{~h}$ at room temperature, the reaction mixture was neutralized with Amberlite IR-120 $\left(\mathrm{H}^{+}\right)$resin, filtered, and concentrated to give the desired amine intermediate. Triethylamine $(33 \mu \mathrm{L}, 0.24 \mathrm{mmol})$ and acetic anhydride $(34 \mu \mathrm{L}, 0.36 \mathrm{mmol})$ were added to a cooled $\left(0^{\circ} \mathrm{C}\right)$ solution of this amine derivative in $\mathrm{MeOH} / \mathrm{H}_{2} \mathrm{O}(2.0 \mathrm{~mL} / 0.5 \mathrm{~mL})$. After stirring for $2 \mathrm{~h}$ at r.t., $\mathrm{Et}_{3} \mathrm{~N}(300 \mu \mathrm{L})$ was added and the mixture was concentrated to dryness. The residue was purified by Sephadex LH-20 $\left(\mathrm{H}_{2} \mathrm{O}-\mathrm{MeOH}\right.$ 9:1), eluted from a column of Dowex 50WX4- $\mathrm{Na}^{+}\left(\mathrm{H}_{2} \mathrm{O}-\right.$ $\mathrm{MeOH}$ 9:1) and lyophilised to obtain $\mathbf{4}$ as sodium salt (9.5 mg, 73\%). TLC (EtOAc/pyridine/ $\mathrm{H}_{2} \mathrm{O} / \mathrm{AcOH}$ 6:5:3:1) Rf $0.23 ;{ }^{1} \mathrm{H}-\mathrm{NMR}\left(400 \mathrm{MHz}, \mathrm{D}_{2} \mathrm{O}\right): \delta$ $4.76\left(\mathrm{~d}, 1 \mathrm{H}, J_{3,4}=2.2 \mathrm{~Hz}, \mathrm{H}-4\right), 4.47\left(\mathrm{~d}, 1 \mathrm{H}, J_{1,2}=7.9 \mathrm{~Hz}, \mathrm{H}-1\right), 4.43(\mathrm{~d}$, $1 \mathrm{H}, \mathrm{J}_{1,2}=7.7 \mathrm{~Hz}, \mathrm{H}-1$ '), 4.23 (dd, 1H, H-6a), 4.13 (dd, 1H, H-6b), 4.05$3.99(\mathrm{~m}, 3 \mathrm{H}, \mathrm{H}-2, \mathrm{H}-3, \mathrm{H}-5), 3.93\left(\mathrm{~m}, 1 \mathrm{H}, \mathrm{CH}_{2}\right), 3.65\left(\mathrm{~m}, 2 \mathrm{H}, \mathrm{H}-5, \mathrm{CH}_{2}\right)$, $3.49\left(\mathrm{t}, 1 \mathrm{H}, J_{3,4}=J_{4,5}=9.3 \mathrm{~Hz}, \mathrm{H}-4^{\prime}\right), 3.40\left(\mathrm{t}, 1 \mathrm{H}, \mathrm{H}-3^{\prime}\right), 3.33-3.28(\mathrm{~m}, 3 \mathrm{H}$, $\left.\mathrm{H}-2, \mathrm{CH}_{2}\right), 1.97(\mathrm{~s}, 3 \mathrm{H}, \mathrm{NHAc}), 1.80\left(\mathrm{~m}, 2 \mathrm{H}, \mathrm{CH}_{2}\right) ;{ }^{13} \mathrm{C}-\mathrm{NMR}(100 \mathrm{MHz}$, $\mathrm{D}_{2} \mathrm{O}$ ): $\delta$ 175.9, 174.7 (CO), $103.2\left(\mathrm{C}-1^{\prime}\right), 101.2(\mathrm{C}-1), 76.4\left(\mathrm{C}-5^{\prime}\right), 76.2$ (C4), 75.1 (C-3'), 74.5 (C-3 or C-5), 72.5 (C-2'), 72.3 (C-5 or C-3), 71.8 (C $\left.4^{\prime}\right), 67.9$ (C-6), $67.4\left(\mathrm{O}-\mathrm{CH}_{2}-\mathrm{CH}_{2}-\mathrm{CH}_{2}-\mathrm{N}_{3}\right), 51.7(\mathrm{C}-2), 47.8\left(\mathrm{O}-\mathrm{CH}_{2}-\mathrm{CH}_{2-}\right.$ $\left.\mathrm{CH}_{2}-\mathrm{N}_{3}\right), 28.1\left(\mathrm{O}-\mathrm{CH}_{2}-\mathrm{CH}_{2}-\mathrm{CH}_{2}-\mathrm{N}_{3}\right), 22.2$ (NHAc); ESI MS: m/z: calcd for $\mathrm{C}_{17} \mathrm{H}_{25} \mathrm{~N}_{4} \mathrm{O}_{18} \mathrm{Na}_{2} \mathrm{~S}_{2}$ : 683.0; found: 683.0 [M-Na]

Dendrimer 16: A solution of $\mathrm{CuSO}_{4} \cdot 5 \mathrm{H}_{2} \mathrm{O}\left(0.3 \mathrm{mg}, 1.25 \times 10^{-3} \mathrm{mmol}\right)$ and TBTA $\left(1.3 \mathrm{mg}, 2.5 \times 10^{-3} \mathrm{mmol}\right)$ in DMSO $(0.5 \mathrm{~mL})$ and a solution of sodium ascorbate $\left(0.7 \mathrm{mg}, 3.7 \times 10^{-3} \mathrm{mmol}\right)$ in $\mathrm{H}_{2} \mathrm{O}(0.1 \mathrm{~mL})$ were added to a solution of 12 (triethylammonium salt, $16 \mathrm{mg}, 0.014 \mathrm{mmol}$ ) and 13 $\left(1.0 \mathrm{mg}, 4.2 \times 10^{-3} \mathrm{mmol}\right)$ in DMSO $(0.5 \mathrm{~mL})$. The solution was stirred at $60{ }^{\circ} \mathrm{C}$ using MW for $45 \mathrm{~min}$. Then, Cu was removed using Quadrasil MP resin and the reaction mixture was purified by size exclusion chromatography Sephadex $\mathrm{LH}-20$ using $\mathrm{MeOH}$ as eluent and by ion exchange DOWEX 50WX4- $\mathrm{Na}^{+}$column $\left(\mathrm{H}_{2} \mathrm{O} / \mathrm{MeOH} 1: 1\right)$ to give 16 as a sodium salt $(8.6 \mathrm{mg}, 63 \%)$. TLC (EtOAc- $\mathrm{MeOH}-\mathrm{H}_{2} \mathrm{O}$ 20:5:3) Rf 0.34; ${ }^{1} \mathrm{H}-\mathrm{NMR}$ (sodium salt, $400 \mathrm{MHz}, \mathrm{CD}_{3} \mathrm{OD}$ ): $\delta 8.08$ (s, 3H, $\mathrm{H}$ triazol), 6.34 (s, 3H, $\mathrm{H}$ aromatic core), $5.32\left(\mathrm{~m}, 6 \mathrm{H}, \mathrm{H}-3^{\prime}, \mathrm{H}-4^{\prime}\right), 5.21-5.14\left(\mathrm{~m}, 9 \mathrm{H}, \mathrm{H}-2^{\prime}\right.$, Triazol- $\mathrm{CH}_{2}-\mathrm{O}$ ), $4.99\left(\mathrm{~d}, 3 \mathrm{H}, J_{1,2}=7.8 \mathrm{~Hz}, \mathrm{H}-1^{\prime}\right), 4.94\left(\mathrm{~d}, 3 \mathrm{H}, J_{3,4}=2.8\right.$ $\mathrm{Hz}, \mathrm{H}-4), 4.54-4.39$ (m, $12 \mathrm{H}, \mathrm{O}-\mathrm{CH}_{2}-\mathrm{CH}_{2}-\mathrm{CH}_{2}$-Triazol, $\left.\mathrm{H}-1, \mathrm{H}-6 \mathrm{a}\right)$, 4.324.10 (m, 12H, H-3, H-5, H-6b, H-2), 3.96 (m, 3H, H-5), 3.85 (m, 3H, O$\mathrm{CH}_{2}-\mathrm{CH}_{2}-\mathrm{CH}_{2}$-Triazol [1 $\left.\left.1 \mathrm{H}\right]\right), 3.74\left(\mathrm{~s}, 9 \mathrm{H}, \mathrm{COOCH}_{3}\right), 3.55\left(\mathrm{~m}, 3 \mathrm{H}, \mathrm{O}-\mathrm{CH}_{2}-\right.$ $\mathrm{CH}_{2}-\mathrm{CH}_{2}$-Triazol $\left.[1 \mathrm{H}]\right), 2.14\left(\mathrm{~m}, 6 \mathrm{H}, \mathrm{O}-\mathrm{CH}_{2}-\mathrm{CH}_{2}-\mathrm{CH}_{2}\right.$-Triazol), $1.14(\mathrm{~s}$ 27H, Piv), 1.10 (s, 54H, 2xPiv); ${ }^{13} \mathrm{C}-\mathrm{NMR}\left(100 \mathrm{MHz}, \mathrm{CD}_{3} \mathrm{OD}\right): \delta 178.4$, 178.2, 169.7 (CO), 161.6 (C aromatic core-O), 126.0 ( $\mathrm{CH}$ triazol), 102.7 (C-1), 101.7 (C-1'), 96.6 (CH aromatic core), 76.9 (C-4), 75.8 (C-3), 74.4 
(C-5), 73.0 (C-3' or C-4'), 72.6 (C-5'), 72.7 (C-2'), 70.9 (C-4' or C-3'), 69.1 (C-6), $67.2\left(\mathrm{O}-\mathrm{CH}_{2}-\mathrm{CH}_{2}-\mathrm{CH}_{2}\right.$-Triazol), 62.4 (Triazol- $\left.\mathrm{CH}_{2}-\mathrm{O}\right), 53.7,53.6$ $\left(\mathrm{CO}_{2} \mathrm{Me}, \mathrm{C}-2\right), 49.0\left(\mathrm{O}-\mathrm{CH}_{2}-\mathrm{CH}_{2}-\mathrm{CH}_{2}-\mathrm{Triazol}\right), 39.7\left(\mathrm{C}\left(\mathrm{CH}_{3}\right)_{3}\right), 31.6(\mathrm{O}-$ $\mathrm{CH}_{2}-\mathrm{CH}_{2}-\mathrm{CH}_{2}$-Triazol), 27.7, 27.6, $27.5\left(3 \times \mathrm{C}\left(\underline{\mathrm{C}} \mathrm{H}_{3}\right)_{3}\right)$; ESI MS: $\mathrm{m} / \mathrm{z}$ : calcd for $\mathrm{C}_{114} \mathrm{H}_{159} \mathrm{~F}_{9} \mathrm{~N}_{12} \mathrm{O}_{66} \mathrm{~S}_{6} \mathrm{Na5}$ : 3229.8; found: 3230.6 [M-Na]'.

Dendrimer 1: A solution of $\mathrm{CuSO}_{4} \cdot 5 \mathrm{H}_{2} \mathrm{O}(3 \mathrm{mg}, 0.012 \mathrm{mmol})$ and TBTA $(12.6 \mathrm{mg}, 0.024 \mathrm{mmol})$ in DMSO/PBS buffer $(10 \mathrm{mM}) 5: 2(0.35 \mathrm{~mL})$ and a solution of sodium ascorbate $(7 \mathrm{mg}, 0.036 \mathrm{mmol})$ in PBS $(10 \mathrm{mM})(0.1$ $\mathrm{mL}$ ) were added to a solution of $4(9.7 \mathrm{mg}, 0.014 \mathrm{mmol})$ and $13(0.8 \mathrm{mg}$, $\left.3.3 \times 10^{-3} \mathrm{mmol}\right)$ in DMSO/PBS buffer $(10 \mathrm{mM}) 5: 2(0.35 \mathrm{~mL})$. The solution was stirred at room temperature overnight. Then, $\mathrm{Cu}$ was removed using Quadrasil MP resin and the reaction mixture was first purified by size exclusion chromatography Sephadex LH-20 using $\mathrm{H}_{2} \mathrm{O} / \mathrm{MeOH}$ 9:1 as eluent and then eluted from an ion exchange DOWEX 50WX4- $\mathrm{Na}^{+}$column $\left(\mathrm{H}_{2} \mathrm{O} / \mathrm{MeOH}\right.$ 9:1) to afford 1 as a sodium salt $(7.7$ mg, quant.). TLC (EtOAc-MeOH- $\mathrm{H}_{2} \mathrm{O}$ 6:5:3) Rf 0.29; ${ }^{1} \mathrm{H}-\mathrm{NMR}(400 \mathrm{MHz}$, $\left.\mathrm{D}_{2} \mathrm{O}\right): \delta 8.00(\mathrm{~s}, 3 \mathrm{H}, \mathrm{H}$ triazol), $6.36(\mathrm{~s}, 3 \mathrm{H}, \mathrm{H}$ aromatic core), $5.16(\mathrm{~s}, 6 \mathrm{H}$, Triazol- $\left.\mathrm{CH}_{2}-\mathrm{O}\right), 4.76(\mathrm{~s}, 3 \mathrm{H}, \mathrm{H}-4), 4.42\left(\mathrm{~m}, 12 \mathrm{H}, \mathrm{H}-1, \mathrm{H}-1\right.$ ', O- $\mathrm{CH}_{2}-\mathrm{CH}_{2-}$ $\mathrm{CH}_{2}$-Triazol), 4.28-4.08 (m, 6H, H-6a, H-6b), 4.06-3.92 (m, 9H, H-2, H-3, $\mathrm{H}-5)$, 3.87-3.77 (m, 3H, O-CH2 $-\mathrm{CH}_{2}-\mathrm{CH}_{2}$-Triazol [1H]), $3.59\left(\mathrm{~d}, 3 \mathrm{H}, \mathrm{J}_{4,5}=\right.$ 9.4 Hz, H-5'), 3.53-3.36 (m, 9H, H-3', H-4', O- $\mathrm{CH}_{2}-\mathrm{CH}_{2}-\mathrm{CH}_{2}$-Triazol [1 $\left.\mathrm{H}\right]$ ), 3.34-3.25 (m, 3H, $\left.\mathrm{H}-2^{\prime}\right), 2.20-2.03\left(\mathrm{~m}, 6 \mathrm{H}, \mathrm{O}-\mathrm{CH}_{2}-\mathrm{CH}_{2}-\mathrm{CH}_{2}\right.$-Triazol), 1.96 (s, 9H, NHAc); ${ }^{13} \mathrm{C}-\mathrm{NMR}\left(100 \mathrm{MHz}, \mathrm{D}_{2} \mathrm{O}\right): \delta 174.8$ (CO), 159.5 (C aromatic core-O), 143.0 (C triazol), $125.2(\mathrm{CH}$ triazol), 103.3 (C-1 or $\mathrm{C}$ 1'), 101.2 (C-1' or C-1), 96.6 ( $\mathrm{CH}$ aromatic core), 76.3 (C-5'), 76.2 (C-4), 75.1 (C-3'), 74.7 (C-3), 72.5 (C-2'), 72.3 (C-5), 71.8 (C-4'), 67.9 (C-6), $66.8\left(\mathrm{O}-\mathrm{CH}_{2}-\mathrm{CH}_{2}-\mathrm{CH}_{2}\right.$-Triazol), 61.5 (Triazol- $\mathrm{CH}_{2}-\mathrm{O}$ ), 51.7 (C-2), 47.1 (O$\mathrm{CH}_{2}-\mathrm{CH}_{2}-\mathrm{CH}_{2}$-Triazol), 29.5 (O- $\mathrm{CH}_{2}-\mathrm{CH}_{2}-\mathrm{CH}_{2}$-Triazol), 22.3 (NHAc); ESI MS: $\mathrm{m} / \mathrm{z}$ : calcd for $\mathrm{C}_{66} \mathrm{H}_{90} \mathrm{~N}_{12} \mathrm{Na}_{4} \mathrm{O}_{57} \mathrm{~S}_{6}:$ 1123.1; found: 1123.2 [M$5 \mathrm{Na}+3 \mathrm{H}]^{2-}$.

Dendrimer 17: A solution of $\mathrm{CuSO}_{4} \cdot 5 \mathrm{H}_{2} \mathrm{O}\left(1.3 \mathrm{mg}, 5.2 \times 10^{-3} \mathrm{mmol}\right)$ and TBTA (5.3 mg, $\left.10.3 \times 10^{-3} \mathrm{mmol}\right)$ in DMSO/ $\mathrm{H}_{2} \mathrm{O} 5: 2(0.35 \mathrm{~mL})$ and a solution of sodium ascorbate $(3 \mathrm{mg}, 0.015 \mathrm{mmol})$ in $\mathrm{H}_{2} \mathrm{O}(0.1 \mathrm{~mL})$ were added to a solution of 12 (sodium salt, $19 \mathrm{mg}, 0.019 \mathrm{mmol}$ ) and $14(1.1$ $\left.\mathrm{mg}, 4.0 \times 10^{-3} \mathrm{mmol}\right)$ in DMSO $(0.5 \mathrm{~mL})$. The solution was stirred at 60 ${ }^{\circ} \mathrm{C}$ using MW for $50 \mathrm{~min}$. Then, $\mathrm{Cu}$ was removed using Quadrasil MP resin and the reaction mixture was purified by size exclusion chromatography Sephadex $\mathrm{LH}-20$ using $\mathrm{MeOH}$ as eluent. The resulting residue was further purified by silica gel column chromatography (EtOAc$\mathrm{MeOH}-\mathrm{H}_{2} \mathrm{O} 30: 5: 3$ ) and then eluted from a column of DOWEX 50WX4$\mathrm{Na}^{+}\left(\mathrm{H}_{2} \mathrm{O}-\mathrm{MeOH} 1: 1\right)$ to afford 17 as a sodium salt $(10.5 \mathrm{mg}, 62 \%)$. TLC (EtOAc-MeOH- $\mathrm{H}_{2} \mathrm{O}$ 20:5:3) Rf 0.18; ${ }^{1} \mathrm{H}-\mathrm{NMR}\left(400 \mathrm{MHz}, \mathrm{CD}_{3} \mathrm{OD}\right.$ ): $\delta 7.90$ (s, $4 \mathrm{H}, \mathrm{H}$ triazol), $5.34\left(\mathrm{t}, 4 \mathrm{H}, J_{2,3}=J_{3,4}=9.1 \mathrm{~Hz}, \mathrm{H}^{\prime} 3^{\prime}\right.$ ), $5.28\left(\mathrm{t}, 4 \mathrm{H}, \mathrm{H}-4^{\prime}\right.$ ), $5.18\left(\mathrm{t}, 4 \mathrm{H}, \mathrm{H}-2^{\prime}\right), 5.01\left(\mathrm{~d}, 4 \mathrm{H}, \mathrm{J}_{1,2}=7.9 \mathrm{~Hz}, \mathrm{H}-1^{\prime}\right), 4.95\left(\mathrm{~d}, 4 \mathrm{H}, J_{3,4}=2.6\right.$ $\mathrm{Hz}, \mathrm{H}-4), 4.57\left(\mathrm{~d}, 4 \mathrm{H}, \mathrm{J}_{1,2}=8.2 \mathrm{~Hz}, \mathrm{H}-1\right), 4.50\left(\mathrm{~s}, 8 \mathrm{H}\right.$, Triazol- $\mathrm{CH}_{2}-\mathrm{O}$ ), 4.43-4.17 (m, 24H, H-3, H-5, H-6, O- $\mathrm{CH}_{2}-\mathrm{CH}_{2}-\mathrm{CH}_{2}$-Triazol), 4.20 (dd, $4 \mathrm{H}, \mathrm{H}-2), 3.96(\mathrm{~m}, 4 \mathrm{H}, \mathrm{H}-5), 3.89\left(\mathrm{~m}, 4 \mathrm{H}, \mathrm{O}-\mathrm{CH}_{2}-\mathrm{CH}_{2}-\mathrm{CH}_{2}\right.$-Triazol $\left.[1 \mathrm{H}]\right)$, $3.76\left(\mathrm{~s}, 12 \mathrm{H}, \mathrm{COOCH}_{3}\right), 3.59\left(\mathrm{~m}, 4 \mathrm{H}, \mathrm{O}-\mathrm{CH}_{2}-\mathrm{CH}_{2}-\mathrm{CH}_{2}-\mathrm{Triazol}[1 \mathrm{H}]\right), 3.43$ (s, $8 \mathrm{H}, \mathrm{CH}_{2}$ pentaerythritol core), $2.10\left(\mathrm{~m}, 8 \mathrm{H}, \mathrm{O}-\mathrm{CH}_{2}-\mathrm{CH}_{2}-\mathrm{CH}_{2}\right.$-Triazol), $1.15\left(\mathrm{~s}, 36 \mathrm{H}, \mathrm{C}\left(\mathrm{CH}_{3}\right)_{3}\right), 1.10\left(\mathrm{~m}, 72 \mathrm{H}, 2 \times \mathrm{C}\left(\mathrm{CH}_{3}\right)_{3}\right) ;{ }^{13} \mathrm{C}-\mathrm{NMR}(100 \mathrm{MHz}$, $\mathrm{CD}_{3} \mathrm{OD}$ ): $\delta 178.3,178.2,169.9(\mathrm{CO}), 146.2$ (C triazol), $125.2(\mathrm{CH}$ triazol), 102.6 (C-1), 101.7 (C-1'), 77.0 (C-4), 75.8 (C-3), 74.5 (C-5), 74.1 (C-3'), 73.1 (C-5'), 72.7 (C-2'), 71.0 (C-4'), $69.8\left(\mathrm{CH}_{2}\right.$ pentaerythritol core), 69.2 (C-6), $67.0 \quad\left(\mathrm{O}-\mathrm{CH}_{2}-\mathrm{CH}_{2}-\mathrm{CH}_{2}\right.$-Triazol), 65.2 (Triazol- $\left.\mathrm{CH}_{2}-\mathrm{O}\right), \quad 53.7$ $\left(\mathrm{CO}_{2} \mathrm{Me}\right), 53.3(\mathrm{C}-2), 48.0\left(\mathrm{O}-\mathrm{CH}_{2}-\mathrm{CH}_{2}-\mathrm{CH}_{2}\right.$-Triazol), $39.7\left(\mathrm{C}\left(\mathrm{CH}_{3}\right)_{3}\right)$, $31.6\left(\mathrm{O}-\mathrm{CH}_{2}-\mathrm{CH}_{2}-\mathrm{CH}_{2}-\mathrm{Triazol}\right), 27.7-27.6\left(\mathrm{C}\left(\mathrm{CH}_{3}\right)_{3}\right)$; ESI MS: $\mathrm{m} / \mathrm{z}$ : calcd for $\mathrm{C}_{149} \mathrm{H}_{218} \mathrm{~F}_{12} \mathrm{~N}_{16} \mathrm{O}_{88} \mathrm{~S}_{8} \mathrm{Na}_{3}: 1398.0$; found: $1398.0[\mathrm{M}-5 \mathrm{Na}+2 \mathrm{H}]^{3-}$.

Dendrimer 2: A solution of $\mathrm{CuSO}_{4} \cdot 5 \mathrm{H}_{2} \mathrm{O}(3.7 \mathrm{mg}, 0.015 \mathrm{mmol})$ and TBTA (15.4 mg, $0.030 \mathrm{mmol}$ ) in DMSO/PBS buffer $(10 \mathrm{mM}) 5: 2(0.35 \mathrm{~mL})$ and a solution of sodium ascorbate $(8.5 \mathrm{mg}, 0.044 \mathrm{mmol})$ in PBS $(10 \mathrm{mM})$ $(0.1 \mathrm{~mL})$ were added to a solution of $4(11.8 \mathrm{mg}, 0.017 \mathrm{mmol})$ and 14 (1 $\left.\mathrm{mg}, 3.5 \times 10^{-3} \mathrm{mmol}\right)$ in DMSO/PBS buffer $(10 \mathrm{mM}) 5: 2(0.35 \mathrm{~mL})$. The solution was stirred at room temperature overnight. Then, $\mathrm{Cu}$ was removed using Quadrasil MP resin and the reaction mixture was first purified by size exclusion chromatography Sephadex LH-20 using $\mathrm{H}_{2} \mathrm{O} / \mathrm{MeOH}$ 9:1 as eluent and then eluted from an ion exchange DOWEX $50 \mathrm{WX} 4-\mathrm{Na}^{+}$column $\left(\mathrm{H}_{2} \mathrm{O} / \mathrm{MeOH} 9: 1\right)$ to afford 2 as a sodium salt $(9.7$ $\mathrm{mg}, 90 \%)$. TLC (EtOAc-MeOH- $\mathrm{H}_{2} \mathrm{O}$ 6:5:3) Rf 0.19; ${ }^{1} \mathrm{H}-\mathrm{NMR}(400 \mathrm{MHz}$, $\left.\mathrm{D}_{2} \mathrm{O}\right): \delta 7.86(\mathrm{~s}, 4 \mathrm{H}, \mathrm{H}$ triazol), $4.77(\mathrm{~s}, 4 \mathrm{H}, \mathrm{H}-4), 4.51-4.40(\mathrm{~m}, 16 \mathrm{H}, \mathrm{H}-1$ $\mathrm{H}-1$ ', Triazol- $\left.\mathrm{CH}_{2}-\mathrm{O}\right), 4.40-4.30\left(\mathrm{~m}, 8 \mathrm{H}, \mathrm{O}-\mathrm{CH}_{2}-\mathrm{CH}_{2}-\mathrm{CH}_{2}\right.$-Triazol), 4.274.07 (m, 8H, H-6a, $\left.\mathrm{H}-6_{\mathrm{b}}\right), 4.06-3.95(\mathrm{~m}, 12 \mathrm{H}, \mathrm{H}-2, \mathrm{H}-3, \mathrm{H}-5)$, 3.88-3.78 (m, $4 \mathrm{H}, \mathrm{O}-\mathrm{CH}_{2}-\mathrm{CH}_{2}-\mathrm{CH}_{2}$-Triazol [1H]), $3.60\left(\mathrm{~d}, 4 \mathrm{H}, \mathrm{J}_{4,5}=9.2 \mathrm{~Hz}, \mathrm{H}-5^{\prime}\right)$, 3.55-3.37 (m, $12 \mathrm{H}, \mathrm{H}-3, \mathrm{H}-4$ ', O- $\mathrm{CH}_{2}-\mathrm{CH}_{2}-\mathrm{CH}_{2}$-Triazol [1H]), 3.37-3.25 ( $\mathrm{m}, 12 \mathrm{H}, \mathrm{H}-2$ ', $\mathrm{CH}_{2}$ pentaerythritol core), 2.16-2.02 (m, 8H, O- $\mathrm{CH}_{2}-\mathrm{CH}_{2}-$ $\mathrm{CH}_{2}$-Triazol), 1.96 (s, $\left.12 \mathrm{H}, \mathrm{NHAc}\right) ;{ }^{13} \mathrm{C}-\mathrm{NMR}\left(100 \mathrm{MHz}, \mathrm{D}_{2} \mathrm{O}\right): \delta 175.9$, 174.7 (2xCO), 144.0 (C triazol), 124.8 ( $\mathrm{CH}$ triazol), $103.3\left(\mathrm{C}-1^{\prime}\right), 101.2$ (C-1), 76.2 (C4, C5'), 75.1 (C-3'), 74.8 (C-3), 72.5 (C-2'), 72.3 (C-5), 71.8 (C-4'), $68.0\left(\mathrm{CH}_{2}\right.$ pentaerythritol core), 67.9 (C-6), $66.8\left(\mathrm{O}-\mathrm{CH}_{2}-\mathrm{CH}_{2}-\mathrm{CH}_{2-}\right.$ Triazol), 63.5 (Triazol- $\left.\mathrm{CH}_{2}-\mathrm{O}\right), 51.7$ (C2), $47.0\left(\mathrm{O}-\mathrm{CH}_{2}-\mathrm{CH}_{2}-\mathrm{CH}_{2}\right.$-Triazol), $29.5\left(\mathrm{O}-\mathrm{CH}_{2}-\mathrm{CH}_{2}-\mathrm{CH}_{2}\right.$-Triazol), 22.3 (NHAc); ESI MS: $\mathrm{m} / z$ : calcd for $\mathrm{C}_{85} \mathrm{H}_{123} \mathrm{~N}_{16} \mathrm{Na}_{6} \mathrm{O}_{76} \mathrm{~S}_{8}$ : 992.4; found: $992.4[\mathrm{M}-6 \mathrm{Na}+3 \mathrm{H}]^{3-}$.

Dendrimer 18: A solution of $\mathrm{CuSO}_{4} \cdot 5 \mathrm{H}_{2} \mathrm{O}\left(1.2 \mathrm{mg}, 4.9 \times 10^{-3} \mathrm{mmol}\right)$ and TBTA (4.9 mg, $\left.9.5 \times 10^{-3} \mathrm{mmol}\right)$ in $\mathrm{DMSO} / \mathrm{H}_{2} \mathrm{O} 5.2(0.35 \mathrm{~mL})$ and a solution of sodium ascorbate $(2.7 \mathrm{mg}, 0.013 \mathrm{mmol})$ in $\mathrm{H}_{2} \mathrm{O}(0.1 \mathrm{~mL})$ were added to a solution of 12 (sodium salt, $17 \mathrm{mg}, 0.017 \mathrm{mmol}$ ) and $15(1.1$ $\left.\mathrm{mg}, 2.4 \times 10^{-3} \mathrm{mmol}\right)$ in DMSO $(0.5 \mathrm{~mL})$. The solution was stirred at $60{ }^{\circ} \mathrm{C}$ using MW for $50 \mathrm{~min}$. Then, Cu was removed using Quadrasil MP resin and the reaction mixture was purified by size exclusion chromatography Sephadex $\mathrm{LH}-20$ using $\mathrm{MeOH}$ as eluent. The resulting residue was further purified by silica gel column chromatography $\left(\mathrm{EtOAc}-\mathrm{MeOH}-\mathrm{H}_{2} \mathrm{O}\right.$ 30:5:3) and then eluted from a column of DOWEX 50WX4- $\mathrm{Na}^{+}\left(\mathrm{H}_{2} \mathrm{O}-\right.$ $\mathrm{MeOH} 1: 1$ ) to afford 18 as a sodium salt (13 mg, 85\%). TLC (EtOAc$\mathrm{MeOH}-\mathrm{H}_{2} \mathrm{O}$ 20:5:3) Rf 0.26; ${ }^{1} \mathrm{H}-\mathrm{NMR}\left(400 \mathrm{MHz}, \mathrm{CD}_{3} \mathrm{OD}\right): \delta 7.92(\mathrm{~s}, 6 \mathrm{H}$ $\mathrm{H}$ triazol), 5.34 (t, $\left.6 \mathrm{H}, J_{2,3}=J_{3,4}=9.2 \mathrm{~Hz}, \mathrm{H}^{\prime} 3^{\prime}\right), 5.27\left(\mathrm{t}, 6 \mathrm{H}, J_{4,5}=9.5 \mathrm{~Hz}\right.$, H-4'), 5.18 (t, $\left.6 \mathrm{H}, \mathrm{H}-2^{\prime}\right), 5.01$ (d, $\left.6 \mathrm{H}, \mathrm{J}_{1,2}=7.8 \mathrm{~Hz}, \mathrm{H}-1^{\prime}\right), 4.96(\mathrm{~s}, 6 \mathrm{H}, \mathrm{H}-$ 4), $4.57\left(\mathrm{~d}, 6 \mathrm{H}, \mathrm{J}_{1,2}=8.2 \mathrm{~Hz}, \mathrm{H}-1\right), 4.49\left(\mathrm{~s}, 12 \mathrm{H}\right.$, Triazol- $\left.\mathrm{CH}_{2}-\mathrm{O}\right), 4.41$ 4.27 (m, 36H, H-3, H-5, H-6a, H-6b, O- $\left.\mathrm{CH}_{2}-\mathrm{CH}_{2}-\mathrm{CH}_{2}-\mathrm{Triazol}\right), 4.19$ (m, $6 \mathrm{H}, \mathrm{H}-2), 3.98-3.84\left(\mathrm{~m}, 12 \mathrm{H}, \mathrm{H}-5, \mathrm{O}-\mathrm{CH}_{2}-\mathrm{CH}_{2}-\mathrm{CH}_{2}\right.$-Triazol [1H]), $3.76(\mathrm{~s}$ $\left.18 \mathrm{H}, \mathrm{COOCH}_{3}\right), 3.57\left(\mathrm{~m}, 6 \mathrm{H}, \mathrm{O}-\mathrm{CH}_{2}-\mathrm{CH}_{2}-\mathrm{CH}_{2}-\mathrm{Triazol}[1 \mathrm{H}]\right), 3.43(\mathrm{~s}, 12 \mathrm{H}$, $\mathrm{CH}_{2}$ pentaerythritol core), $3.32\left(\mathrm{~m}, 4 \mathrm{H}, \mathrm{C}-\mathrm{CH}_{2}-\mathrm{O}-\mathrm{CH}_{2}-\mathrm{C}\right.$ pentaerythritol core $)$ 2.22-2.00 (m, $12 \mathrm{H}, \quad \mathrm{O}-\mathrm{CH}_{2}-\mathrm{CH}_{2}-\mathrm{CH}_{2}$-Triazol), $1.15(\mathrm{~s}, 54 \mathrm{H}$, $\left.\mathrm{C}\left(\mathrm{CH}_{3}\right)_{3}\right), 1.10\left(\mathrm{~m}, 108 \mathrm{H}, 2 \times \mathrm{C}\left(\mathrm{CH}_{3}\right)_{3}\right) ;{ }^{13} \mathrm{C}-\mathrm{NMR}(100 \mathrm{MHz}$, selected data obtained from $\left.\mathrm{HSQC}, \mathrm{CD}_{3} \mathrm{OD}\right): \delta 124.7(\mathrm{CH}$ triazol), $102.4(\mathrm{C}-1), 101.4$ (C-1'), 76.7 (C-4), 75.4 (C-3), 74.1 (C-5), 73.7 (C-3'), 72.8 (C-5'), 72.3 (C 2'), 70.7 (C-4'), $70.6\left(\mathrm{C}-\mathrm{CH}_{2}-\mathrm{O}-\mathrm{CH}_{2}-\mathrm{C}\right.$ pentaerythritol core), $70.0\left(\mathrm{CH}_{2}\right.$ pentaerythritol core), 68.8 (C-6), $66.8\left(\mathrm{O}-\mathrm{CH}_{2}-\mathrm{CH}_{2}-\mathrm{CH}_{2}\right.$-Triazol), 65.1 (Tria- $\left.\mathrm{CH}_{2}-\mathrm{O}\right)$, $53.4\left(\mathrm{CO}_{2} \mathrm{CH}_{3}\right), 53.0(\mathrm{C}-2), 48.0\left(\mathrm{O}-\mathrm{CH}_{2}-\mathrm{CH}_{2}-\mathrm{CH}_{2}\right.$-Triazol), $31.3\left(\mathrm{O}-\mathrm{CH}_{2}-\mathrm{CH}_{2}-\mathrm{CH}_{2}\right.$-Triazol), $27.4\left(\mathrm{C}\left(\mathrm{CH}_{3}\right)_{3}\right) ;$ MALDI-TOF MS: $\mathrm{m} / \mathrm{z}$ calcd for $\mathrm{C}_{226} \mathrm{H}_{340} \mathrm{~F}_{18} \mathrm{~N}_{24} \mathrm{O}_{100 \mathrm{~S}}$ : 5364.2; found: $5364.6\left[\mathrm{M}-11 \mathrm{SO}_{3} \mathrm{Na}-\right.$ $\mathrm{Na}+11 \mathrm{H}]$

Dendrimer 3: A solution of $\mathrm{CuSO}_{4} \cdot 5 \mathrm{H}_{2} \mathrm{O}(2.6 \mathrm{mg}, 0.010 \mathrm{mmol})$ and TBTA (11.1 mg, $0.020 \mathrm{mmol})$ in DMSO/PBS buffer (10mM) $5: 2(0.35 \mathrm{~mL})$ and a solution of sodium ascorbate $(6.1 \mathrm{mg}, 0.030 \mathrm{mmol})$ in PBS $(10 \mathrm{mM})$ $(0.1 \mathrm{~mL})$ were added to a solution of $4(11.2 \mathrm{mg}, 0.016 \mathrm{mmol})$ and 15 $\left(0.8 \mathrm{mg}, 1.7 \times 10^{-3} \mathrm{mmol}\right)$ in DMSO/PBS buffer $(10 \mathrm{mM}) 5: 2(0.35 \mathrm{~mL})$. The solution was stirred at room temperature overnight. Then, $\mathrm{Cu}$ was removed using Quadrasil MP resin and the reaction mixture was first purified by size exclusion chromatography Sephadex LH-20 using $\mathrm{H}_{2} \mathrm{O} / \mathrm{MeOH}$ 9:1 as eluent and then eluted from a column of DOWEX $50 \mathrm{WX} 4-\mathrm{Na}^{+}\left(\mathrm{H}_{2} \mathrm{O} / \mathrm{MeOH} 9: 1\right)$ to afford 3 as a sodium salt $(7.6 \mathrm{mg}$, quant.). TLC (EtOAc-MeOH-H ${ }_{2} \mathrm{O}$ 6:5:3) Rf 0.18; ${ }^{1} \mathrm{H}-\mathrm{NMR}(400 \mathrm{MHz}$, $\left.\mathrm{D}_{2} \mathrm{O}\right): \delta 7.85(\mathrm{~s}, 6 \mathrm{H}, \mathrm{H}$ triazol), $4.77(\mathrm{~s}, 6 \mathrm{H}, \mathrm{H}-4), 4.52-4.29(\mathrm{~m}, 36 \mathrm{H}, \mathrm{H}-1$, $\mathrm{H}-1$ ', Triazol- $\mathrm{CH}_{2}-\mathrm{O}, \mathrm{O}-\mathrm{CH}_{2}-\mathrm{CH}_{2}-\mathrm{CH}_{2}-$ Triazol), 4.27-4.07 (m, $12 \mathrm{H}, \mathrm{H}-6 \mathrm{a}$, 
$\mathrm{H}-6 \mathrm{~b}), 4.06-3.95(\mathrm{~m}, 18 \mathrm{H}, \mathrm{H}-2, \mathrm{H}-3, \mathrm{H}-5), 3.89-3.78\left(\mathrm{~m}, 6 \mathrm{H}, \mathrm{O}-\mathrm{CH}_{2}-\mathrm{CH}_{2}-\right.$ $\mathrm{CH}_{2}$-Triazol [1H]), $3.62\left(\mathrm{~d}, 6 \mathrm{H}, \mathrm{J}_{4,5}=8.8 \mathrm{~Hz}, \mathrm{H}-5^{\prime}\right), 3.55-3.38(\mathrm{~m}, 18 \mathrm{H}, \mathrm{H}-$ 3', H-4', O- $\mathrm{CH}_{2}-\mathrm{CH}_{2}-\mathrm{CH}_{2}$-Triazol [1H]), 3.38-3.24 (m, 18H, H-2', $\mathrm{CH}_{2}$ pentaerythritol core), $3.18\left(\mathrm{~s}, 4 \mathrm{H}, \mathrm{C}-\mathrm{CH}_{2}-\mathrm{O}-\mathrm{CH}_{2}-\mathrm{C}\right.$ pentaerythritol core), 2.16-2.01 (m, $12 \mathrm{H}, \quad \mathrm{O}-\mathrm{CH}_{2}-\mathrm{CH}_{2}-\mathrm{CH}_{2}-\mathrm{Triazo}^{2}, 1.96$ (s, 18H, NHAc); ${ }^{13} \mathrm{C}-\mathrm{NMR}\left(100 \mathrm{MHz}, \mathrm{D}_{2} \mathrm{O}\right): \delta$ 175.9, 174.7 (2xCO), 144.1 (C triazol), 124.7 (CH triazol), 103.4 (C-1'), 101.2 (C-1), 76.3 (C4, C5'), 75.1 (C-3'), 75.0 (C-3), 72.6 (C-2'), 72.3 (C-5), $71.9\left(\mathrm{C}^{\prime} 4^{\prime}\right), 68.4\left(\mathrm{CH}_{2}\right.$ pentaerythritol core), 67.9 (C-6), $66.8\left(\mathrm{O}-\mathrm{CH}_{2}-\mathrm{CH}_{2}-\mathrm{CH}_{2}\right.$-Triazol), 63.6 (Triazol- $\left.\mathrm{CH}_{2}-\mathrm{O}\right)$, 51.7 (C-2), $47.0\left(\mathrm{O}-\mathrm{CH}_{2}-\mathrm{CH}_{2}-\mathrm{CH}_{2}\right.$-Triazol), 45.0, $29.6\left(\mathrm{O}-\mathrm{CH}_{2}-\mathrm{CH}_{2}-\mathrm{CH}_{2}\right.$ Triazol), 22.4 (NHAc); ESI MS: $\mathrm{m} / z$ : calcd for $\mathrm{C}_{130} \mathrm{H}_{187} \mathrm{~N}_{24} \mathrm{Na}_{12} \mathrm{O}_{115} \mathrm{~S}_{12}$ : 1528.2; found: $1528.8[\mathrm{M}-6 \mathrm{Na}+3 \mathrm{H}]^{3}$.

Disaccharide 19: A solution of $\mathrm{CuSO}_{4} \cdot 5 \mathrm{H}_{2} \mathrm{O}(3.1 \mathrm{mg}, 0.012 \mathrm{mmol})$ and TBTA (13.3 mg, $0.024 \mathrm{mmol})$ in DMSO/PBS buffer $(10 \mathrm{mM}) 5: 2(0.35 \mathrm{~mL})$ and a solution of sodium ascorbate $(8.0 \mathrm{mg}, 0.040 \mathrm{mmol})$ in PBS $(10 \mathrm{mM})$ $(0.1 \mathrm{~mL})$ were added to a solution of $4(8.4 \mathrm{mg}, 0.012 \mathrm{mmol})$ and propargyl alcohol $(1.4 \mu \mathrm{L}, 0.024 \mathrm{mmol})$ in DMSO/PBS buffer (10mM) 5:2 $(0.35 \mathrm{~mL})$. The solution was stirred at room temperature overnight. Then, Cu was removed using Quadrasil MP resin and the reaction mixture was first purified by size exclusion chromatography Sephadex LH-2O using $\mathrm{H}_{2} \mathrm{O} / \mathrm{MeOH}$ 9:1 as eluent and then eluted from a column of DOWEX $50 \mathrm{WX} 4-\mathrm{Na}^{+}\left(\mathrm{H}_{2} \mathrm{O} / \mathrm{MeOH}\right.$ 9:1) to afford 19 as a sodium salt $(9.6 \mathrm{mg}$ quant.). TLC (EtOAc-MeOH- $\mathrm{H}_{2} \mathrm{O}$ 12:5:3) Rf $0.21 ;{ }^{1} \mathrm{H}-\mathrm{NMR}(400 \mathrm{MHz}$, $\left.\mathrm{D}_{2} \mathrm{O}\right): \delta 7.89\left(\mathrm{~s}, 1 \mathrm{H}, \mathrm{H}\right.$ triazol), $4.76(\mathrm{~s}, 1 \mathrm{H}, \mathrm{H}-4), 4.65\left(\mathrm{~s}, 2 \mathrm{H}\right.$, Triazol $-\mathrm{CH}_{2}-$ $\mathrm{OH}$ ), 4.45-4.42 (m, 4H, H-1, H-1', O- $\mathrm{CH}_{2}-\mathrm{CH}_{2}-\mathrm{CH}_{2}$-Triazol), 4.25-4.11 (m, 2H, H-6a, H-6b), 4.04-3.99 (m, 3H, H-2, H-3, H-5), 3.85-3.80 (m, 1H, O$\mathrm{CH}_{2}-\mathrm{CH}_{2}-\mathrm{CH}_{2}$-Triazol [1H]), $3.63\left(\mathrm{~d}, 1 \mathrm{H}, \mathrm{J}_{4,5}=9.6 \mathrm{~Hz}, \mathrm{H}-5\right.$ '), 3.55-3.45 $\left(\mathrm{m}, 2 \mathrm{H}, \mathrm{H}-4\right.$, O- $\mathrm{CH}_{2}-\mathrm{CH}_{2}-\mathrm{CH}_{2}$-Triazol [1H]), $3.40\left(\mathrm{t}, 1 \mathrm{H}, \mathrm{J}_{2,3}=J_{3,4}=9.1\right.$ $\left.\mathrm{Hz}, \mathrm{H}-3^{\prime}\right), 3.31$ (t, $\left.1 \mathrm{H}, \mathrm{J}_{1,2}=8.4 \mathrm{~Hz}, \mathrm{H}-2^{\prime}\right), 2.13-2.10\left(\mathrm{~m}, 2 \mathrm{H}, \mathrm{O}-\mathrm{CH}_{2}-\mathrm{CH}_{2}-\right.$ $\mathrm{CH}_{2}$-Triazol), 1.96 (s, 3H, NHAc); ${ }^{13} \mathrm{C}-\mathrm{NMR}\left(100 \mathrm{MHz}, \mathrm{D}_{2} \mathrm{O}\right): \delta 175.4$, 174.7 (2xCO), 124.7 ( $\mathrm{CH}$ triazol), $103.2\left(\mathrm{C}-1^{\prime}\right), 101.1(\mathrm{C}-1), 76.2(\mathrm{C} 4$, C5'), 75.1 (C-3'), 74.7 (C-3), 72.4 (C-2'), 72.3 (C-5), 71.7 (C-4'), 68.0 (C6), $66.8\left(\mathrm{O}-\mathrm{CH}_{2}-\mathrm{CH}_{2}-\mathrm{CH}_{2}\right.$-Triazol), 54.6 (Triazol- $\left.\mathrm{CH}_{2}-\mathrm{OH}\right), 51.7$ (C-2), 47.0 (O- $\left.\mathrm{CH}_{2}-\mathrm{CH}_{2}-\mathrm{CH}_{2}-\mathrm{Triazol}\right) \quad 29.4 \quad\left(\mathrm{O}-\mathrm{CH}_{2}-\mathrm{CH}_{2}-\mathrm{CH}_{2}-\right.$ Triazol), 22.3 (NHAC); ESI MS: $m / z$ : calcd for $\mathrm{C}_{20} \mathrm{H}_{29} \mathrm{~N}_{4} \mathrm{Na}_{2} \mathrm{O}_{19} \mathrm{~S}_{2}$ : 739.1 ; found: 739.0 $[M-\mathrm{Na}]$.

\section{Fluorescence polarization assays}

Fluorescence polarization measurements were performed in 384-well microplates (black polystyrene, non-treated, Corning). The fluorescence polarization was recorded using a TRIAD multimode microplate reader (from Dynex), with excitation and emission wavelengths of 485 and 535 $\mathrm{nm}$, respectively. The fluorescent probe (a fluorescein labelled heparinlike hexasaccharide previously prepared in our lab) ${ }^{[18]}$ was dissolved in PBS buffer (10 mM, pH 7.4). Recombinant human midkine (Peprotech) was dissolved in PBS buffer (10 mM, pH 7.4) containing 1\% BSA (bovine serum albumin). Compounds 1-4 and $\mathbf{1 9}$ were dissolved in PBS buffer (10 mM, pH 7.4).

For the determination of the $\mathrm{IC}_{50}$ values, we recorded the fluorescence polarization from wells containing $20 \mu \mathrm{L}$ of a $125 \mathrm{nM}$ midkine solution and $10 \mu \mathrm{L}$ of a $40 \mathrm{nM}$ probe solution in the presence of $10 \mu \mathrm{L}$ of inhibitor solution, with concentrations ranging from $100 \mu \mathrm{M}$ to $100 \mathrm{nM}$ (from $3 \mathrm{mM}$ to $100 \mu \mathrm{M}$, in the case of 19). The microplate was shaked in the dark for $5 \mathrm{~min}$, before reading. The total sample volume in each well was $40 \mu \mathrm{L}$ and the final buffer composition was PBS $+0.5 \%$ BSA. The final concentrations of fluorescent probe and midkine in each well were $10 \mathrm{nM}$ and $63 \mathrm{nM}$, respectively, while the final inhibitor concentration ranged from $25 \mu \mathrm{M}$ to $25 \mathrm{nM}$ (from $0.75 \mathrm{mM}$ to $25 \mu \mathrm{M}$, in the case of 19). The average polarization values of three replicates were plotted against the logarithm of inhibitor concentration. Two control samples were included in the competition experiment. The first one only contained fluorescent probe and afforded the expected minimum polarization value for $100 \%$ inhibition; the second one contained midkine and probe, in the absence of inhibitor, and gave the maximum polarization value corresponding to $0 \%$ inhibition. Blank wells contained $20 \mu \mathrm{L}$ of midkine solution (125 nM) and $20 \mu \mathrm{L}$ of a $50 \mu \mathrm{M}$ inhibitor solution and their measurements were subtracted from all values. The curve was fitted to the equation for a onesite competition: $y=A_{2}+\left(A_{1}-A_{2}\right) /\left[1+10^{\wedge}\left(x-\log \mid C_{50}\right)\right]$ where $A_{1}$ and $A_{2}$ arethe maximal and minimal values of polarization, respectively, and $\mathrm{IC}_{50}$ is the inhibitor concentration that results in $50 \%$ inhibition. At least three independent experiments were carried out for each $\mathrm{IC}_{50}$ calculation.

\section{Acknowledgements}

We would like to acknowledge MINECO for grants (CTQ201452328-P, CTQ2015-70134-P), Junta de Andalucía (FQM-1303), co-financed by European Regional Development Funds (ERDF). JJR thanks CSIC for a JAE-DOC contract. PD-R and SG-C thanks Junta de Andalucía for a predoctoral and postdoctoral contract, respectively.

Keywords: dendrimers • glycomimetics • GAG • cytokines • multivalency

[1] a) K. Sugahara, T. Mikami, T. Uyama, S. Mizuguchi, K. Nomura and H. Kitagawa, Curr. Opin. Struct. Biol. 2003, 13, 612-620; b) C. I. Gama and L. C. Hsieh-Wilson, Curr. Opin. Chem. Biol. 2005, 9, 609-619.

[2] a) S. Mizumoto, S. Yamada and K. Sugahara, Curr. Opin. Struct. Biol. 2015, 34, 35-42; b) C. J. Rogers, P. M. Clark, S. E. Tully, R. Abrol, K. C. Garcia, W. A. Goddard, III and L. C. Hsieh-Wilson, Proc. Natl. Acad. Sci. USA 2011, 108, 9747-9752.

[3] A. Pulsipher, M. E. Griffin, S. E. Stone, J. M. Brown and L. C. HsiehWilson, J. Am. Chem. Soc. 2014, 136, 6794-6797.

[4] a) S. S. Deepa, Y. Umehara, S. Higashiyama, N. Itoh and K. Sugahara, J. Biol. Chem 2002, 277, 43707-43716; b) H. Kawashima, K. Atarashi, M. Hirose, J. Hirose, S. Yamada, K. Sugahara and M. Miyasaka, J. Biol. Chem. 2002, 277, 12921-12930.

[5] a) K. Miyachi, M. Wakao and Y. Suda, Bioorg. Med. Chem. Lett. 2015, 25, 1552-1555; b) J.-C. Jacquinet and C. Lopin-Bon, Carbohydr. Res. 2015, 402 , 35-43; c) J.-i. Tamura, N. Tsutsumishita-Nakai, Y. Nakao, M. Kawano, S. Kato N. Takeda, S. Nadanaka and H. Kitagawa, Bioorg. Med. Chem. Lett. 2012, 22, 1371-1374; d) S. E. Tully, R. Mabon, C. I. Gama, S. M. Tsai, X. W. Liu and L. C. Hsieh-Wilson, J. Am. Chem. Soc. 2004, 126, 7736-7737; e) E. Bedini and M. Parrilli, Carbohydr. Res. 2012, 356, 75-85; f) S. Eller, M. Collot, J. Yin, H. S. Hahm and P. H. Seeberger, Angew. Chem. Int. Ed. 2013, 52, 5858-5861; g) G. Macchione, S. Maza, M. M. Kayser, J. L. de Paz and P. M. Nieto, Eur. J. Org. Chem. 2014, 2014, 3868-3884; h) G. Despras, C. Bernard, A. Perrot, L. Cattiaux, A. Prochiantz, H. Lortat-Jacob and J.-M. Mallet, Chem. Eur. J. 2013 19, 530-539; i) A Vibert, C. Lopin-Bon and J. C Jacquinet, Chem Eur. J. 2009, 15, 9561-9578; j) J. C. Jacquinet, C. Lopin-Bon and A. Vibert, Chem. Eur. J. 2009, 15, 9579-9595; k) J. Tamura, Y. Nakada, K. Taniguchi and M. Yamane, Carbohydr. Res. 2008, 343, 39-47; I) N. A. Karst, R. J. Linhardt Curr. Med. Chem. 2003, 10, 1993-2031.

[6] a) J. J. Lundquist and E. J. Toone, Chem. Rev. 2002, 102, 555-578; b) M. Mammen, S. K. Choi and G. M. Whitesides, Angew. Chem. Int. Ed. 1998, 37 2755-2794; c) R. Roy, P. V. Murphy and H.-J. Gabius, Molecules 2016, 21 629

[7] a) A. K. Adak, H.-J. Lin and C.-C. Lin, Org. Biomol. Chem. 2014, 12, 5563 5573; b) A. Bernardi, J. Jimenez-Barbero, A. Casnati, C. De Castro, T. Darbre, F. Fieschi, J. Finne, H. Funken, K.-E. Jaeger, M. Lahmann, T. K. Lindhorst, M. Marradi, P. Messner, A. Molinaro, P. V. Murphy, C. Nativi, S. Oscarson, S. Penades, F. Peri, R. J. Pieters, O. Renaudet, J.-L. Reymond, B. Richichi, J. Rojo, F. Sansone, C. Schaeffer, W. B. Turnbull, T. Velasco-Torrijos, S. Vidal S. Vincent, T. Wennekes, H. Zuilhof and A. Imberty, Chem. Soc. Rev. 2013 42, 4709-4727; c) B. Lepenies, J. Lee and S. Sonkaria, Adv. Drug Deliv. Rev. 2013, 65, 1271-1281; d) M. Marradi, F. Chiodo, I. Garcia and S. Penades, Chem Soc Rev 2013, 42 4728-4745; e) C. Mueller G. Despras and T. K. Lindhorst, Chem. Soc. Rev. 2016, 45, 3275-3302; f) J. J. Reina and J. Rojo, Braz. J. Pharm. Sci. 2013, 49, 109-124; g) R. Roy, Curr. Opin. Struct. Biol. 1996, 6, 692-702; h) M. Sanchez-Navarro and J. Rojo, Drug News Perspect. 2010, 23, 557-572; i) W. B. Turnbull and J. F. Stoddart, Rev. Mol. Biotechnol. 2002, 90, 231-255, (j) J. J. Reina, J. Rojo in Carbohydrate Chemistry: State of 
the Art and Challenges for Drug Development (Ed.: L. Cipolla), Imperial College Press, 2013, pp. 419-439.

[8] a) J. L. de Paz, C. Noti, F. Bohm, S. Werner and P. H. Seeberger, Chem. Biol. 2007, 14, 879-887; b) P. C. Tyler, S. E. Guimond, J. E. Turnbull and O. V. Zubkova, Angew. Chem. Int. Ed. 2015, 54, 2718-2723; c) Y. I. Oh, G. J. Sheng, S.-K. Chang and L. C. Hsieh-Wilson, Angew. Chem. Int. Ed. 2013, 52 , 11796-11799; d) G. J. Sheng, Y. I. Oh, S.-K. Chang and L. C. Hsieh-Wilson, J. Am. Chem. Soc. 2013, 135, 10898-10901.

[9] a) M. Rawat, C. I. Gama, J. B. Matson and L. C. Hsieh-Wilson, J. Am Chem. Soc. 2008, 130, 2959-2961; b) S.-G. Lee, J. M. Brown, C. J. Rogers, J. B. Matson, C. Krishnamurthy, M. Rawat and L. C. Hsieh-Wilson, Chem. Sci. 2010, 1, 322-325.

[10] P. Liu, L. Chen, J. K. C. Toh, Y. L. Ang, J.-E. Jee, J. Lim, S. S. Lee and S.-G. Lee, Chem. Sci. 2015, 6, 450-456.

[11] C. Solera, G. Macchione, S. Maza, M. M. Kayser, F. Corzana, J. L. de Paz and P. M. Nieto, Chem. Eur. J. 2016, 22, 2356-2369.

[12] J. R. Harding, C. D. King, J. A. Perrie, D. Sinnott and A. V. Stachulski, Org. Biomol. Chem. 2005, 3, 1501-1507.
[13] S. Maza, J. L. de Paz and P. M. Nieto, Tetrahedron Lett. 2011, 52, 441 443.

[14] N. Varga, I. Sutkeviciute, R. Ribeiro-Viana, A. Berzi, R. Ramdasi, A Daghetti, G. Vettoretti, A. Amara, M. Clerici, J. Rojo, F. Fieschi and A Bernardi, Biomaterials 2014, 35, 4175-4184.

[15] J. L. de Paz and M. Martin-Lomas, Eur. J. Org. Chem. 2005, 1849-1858.

[16] a) T. Muramatsu, Curr. Pharm. Des. 2011, 17, 410-423; b) K. Kadomatsu, S. Kishida and S. Tsubota, J. Biochem. 2013, 153, 511-521.

[17] a) C. I. Gama, S. E. Tully, N. Sotogaku, P. M. Clark, M. Rawat, N. Vaidehi, W. A. Goddard, A. Nishi and L. C. Hsieh-Wilson, Nat. Chem. Biol. 2006, 2, 467-473; b) J. L. de Paz and P. M. Nieto, Org. Biomol. Chem. 2016 14, 3506-3509

[18] S. Maza, M. Mar Kayser, G. Macchione, J. Lopez-Prados, J. Angulo, J. L. de Paz and P. M. Nieto, Org. Biomol. Chem. 2013, 11, 3510-3525. 
Entry for the Table of Contents (Please choose one layout)

Layout 2:

\section{FULL PAPER}

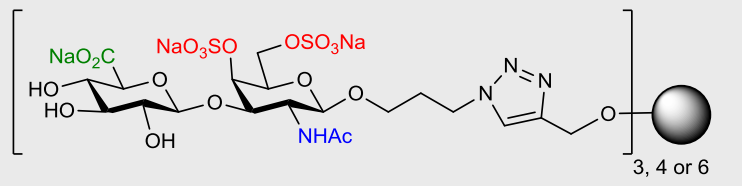

Chondroitin sulfate (CS) analogs in one click. Dendrimers displaying CS disaccharides were efficiently synthesized. These multivalent systems showed high protein binding affinities, mimicking the activity of this biologically relevant polysaccharide.
Pedro Domínguez-Rodríguez, José J. Reina, Sergio Gil-Caballero, Pedro M. Nieto, * José L. de Paz, * and Javier Rojo*

Page No. - Page No.

Glycodendrimers as chondroitin sulfate mimetics: synthesis and binding to growth factor midkine 